\title{
Aligning Financial Intermediary Investments with the Paris Agreement
}

\author{
Sophie Fuchs, Aki Kachi, Lauren Sidner, Michael Westphal \\ With contributions from Ben Lawless and David Ryfisch
}

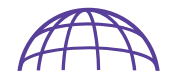

GERMANWATCH

Uty

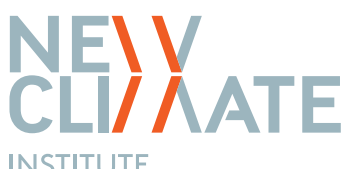

INSTITUTE
WORLD

RESOURCES

IN S T I T UTE

\section{Executive Summary}

\section{Highlights}

- Development finance institutions (DFIs) play a key role in achieving the Paris Agreement's goal of aligning financial flows with low-emission, climate-resilient development pathways. Many DFIs have committed to aligning their investments with the objectives of the Paris Agreement.

- To date, efforts to align DFI investments have primarily focused on direct project financing. However, most DFIs channel substantial portions of their finance through financial intermediaries. To be fully aligned with global climate goals, DFIs must also align these "indirect" investments.

- We propose a phased approach for aligning indirect investments that includes both subproject-level criteria reflecting mitigation and adaptation requirements and institutional-level criteria related to climate governance and transparency in financial intermediaries.

- Ultimately, DFIs are responsible for ensuring that their intermediated investments are aligned with climate goals. We conclude with recommendations for how DFIs can align these investments through institutional changes within the DFI and a risk-tailored approach to choosing investment instruments.

\section{Contents}

Executive Summary

1. Importance of Aligning Development Finance Institutions' Intermediated Investments with the Paris Agreement..... 5

2. Framework for Paris-Aligned Intermediated Finance...

3. DFI Engagement and Support for FIs Not Ready to Commit to Implementing Paris Alignment Criteria within the

Required Timeline. 26

4. Operational Implications for DFIs. .28

Endnotes .28

References .29

Working Papers contain preliminary research, analysis, findings, and recommendations. They are circulated to stimulate timely discussion and critical feedback, and to influence ongoing debate on emerging issues. Working papers may eventually be published in another form and their content may be revised.

SUGGESTED CITATION: Fuchs S., et. al. 2021. "Aligning Financial Intermediary Investments with the Paris Agreement." Working Paper. Washington, DC: World Resources Institute. Available online at https://doi.org/10.46830/wriwp.20.00037 


\section{Problem Statement}

Development finance institutions (DFIs) play a key role in achieving the Paris Agreement's goal of aligning financial flows with low-emission, climate-resilient development pathways. Together, development banks invest more than US\$2 trillion per year (AFD 2020a). Key DFIs, including multilateral development banks and the International Development Finance Club, ${ }^{1}$ have committed to aligning their operations with the Paris Agreement. But, so far, they have focused on developing and implementing Paris alignment processes for direct financing - that is, financing that goes directly to projects like new infrastructure or agricultural initiatives.

Financial intermediary (FI) lending represents a substantial portion of overall lending for most of the 17 DFls analyzed in this working paper. These institutions have not yet developed Paris alignment criteria for FI investments. ${ }^{2}$ For example, at the International Finance Corporation (IFC), more than 60 percent of all commitments are channeled through intermediaries. At the European Bank for Reconstruction and Development and European Investment Bank (EIB), about a third of all commitments are channeled through Fls. If FI lending is not Paris aligned, then these institutions cannot claim to be Paris aligned.

This paper proposes an approach DFIs could adopt to align their Fl investments. It aims to inform DFI management and board member decisions regarding the development, implementation, and oversight of intermediated lending considering the DFI's commitments to support the objectives of the Paris Agreement. As shareholders, DFI board members have the responsibility to support institutional changes in DFIs and Fls by providing necessary resources and holding DFIs accountable for aligning bank strategies and operations with the Paris climate goals.

\section{About This Paper}

The proposed framework is based on a multipronged research approach. Research began with an analysis of existing $\mathrm{Fl}$ investments using DFI project databases to determine the volume and types of $\mathrm{Fl}$ investments at the various DFls. It also included a comprehensive survey of existing DFI policies and practices, including those related to environmental and social safeguards and those specific to financial intermediaries. Research focused on the World Bank Group (including the IFC), EIB, Asian Development Bank, and Inter-American Development Bank, as well as the French bilateral lender Agence Française de Développement (French Development Agency) and German Kreditanstalt für Wiederaufbau (KfW; Credit Institute for Reconstruction). It further drew lessons from evaluations by DFI independent evaluation bodies and third-party observers.

Although individual DFls are beginning to take constructive steps to improve environmental and climate-related due diligence for their intermediated investments, on the whole, our literature review confirmed that much more is needed for DFls to align their investments through financial intermediaries. Building on this baseline, the research drew on discussions and written input from DFI shareholders, staff, and other stakeholders; literature on technologies and activities that align with the global temperature goal; as well as the authors' expertise based on past research relating to DFIs and Paris alignment (see, for example, Germanwatch and NewClimate Institute 2018; Larsen et al. 2018).

The paper aims to present a robust yet practical approach for DFIs to follow to align their intermediated investments with the Paris Agreement-minimizing the risk that indirect DFI investments will support misaligned activities while also recognizing capacity, data, and resource constraints. In developing a proposed approach, several important challenges became clear. The diversity of financial intermediaries-from small leasing companies to large private commercial banks and national development banks - and the various ways that DFIs interact with them requires a strategy that can be adapted to account for different circumstances. The diversity of financial instruments involved and differences in internal capacity mean that support and resources must be dedicated to both DFIs and their FI counterparties to allow them to implement, track, and monitor compliance with Paris alignment requirements. 


\section{Proposed Approach for Aligning Indirect Investments with Paris Agreement Goals}

Under our proposed approach, DFIs would ensure that FIs comply with Paris alignment criteria under four pillars: mitigation, adaptation, governance, and transparency. At the subproject level, Fls would adopt criteria to ensure that their investments are consistent with the Paris Agreement's global mitigation and adaptation goals. At the institutional level, Fls would adopt relevant climate governance structures and reporting measures. We propose a phased approach where DFIs ensure that Fls fulfill certain requirements immediately (phase 1) and more stringent requirements over a predefined period of up to five years (phase 2).

Ultimately, the onus is on the DFIs to ensure that their intermediated finance is Paris aligned. While many of the proposed requirements fall on Fls to implement, DFIs are responsible for ensuring that Fls adopt the required criteria and processes under each of the four pillars. The DFIs' role is also to create awareness, build capacity, and track progress toward Paris alignment.

To align with mitigation goals, DFls would require Fls to apply sector-specific alignment criteria. To be Paris aligned, Fls would need to immediately exclude any new coal-related investments. This includes coal investments using funds that do not come from the DFI. In addition, Fls would apply a Paris-aligned exclusion list to new investments in other sectors that can readily be decarbonized (e.g., power, road, rail transport). For sectors that cannot be readily decarbonized (e.g., steel, cement, agriculture), Fls would adopt sector-specific standards and criteria to assess subproject alignment.

To align with adaptation goals, DFls would require Fls to assess their planned investments for physical climate risks. At a minimum, Fls would need to conduct qualitative risk screening. Over time, they would need to build up the capacity to conduct more comprehensive risk assessments, potentially including robust quantitative risk assessments, for projects identified as having medium and high climate-related risk. Fls would then use these assessments to incorporate climate resilience into the design of investment projects.

At the institutional level, DFls would require Fls to meet a series of requirements relating to governance and transparency. Governance requirements would include making a high-level commitment to Paris alignment and ensuring sufficient staff capacity to implement mitigation and adaptation requirements. For transparency, DFIs would require Fls to report on the sector breakdown of their overall investment portfolios, provide details on subprojects financed using DFI funds, and disclose mitigation and adaptation assessments. Within five years, Fls should also report on climate finance and disclose climate-related risk and opportunities according to the guidelines of the Task Force on Climate-Related Financial Disclosures.

Under the proposed approach, DFls would also need to carefully select the investment instruments they use in FI projects, as different instruments pose varying levels of risk. General purpose lending and equity investments introduce the greatest risk of supporting misaligned investments. As such, DFls would adopt a precautionary approach when using these tools. Specifically, they would offer general purpose loans and equity investments only to Fls that either already satisfy phase 1 Paris alignment criteria under all four pillars and have committed to implementing the phase 2 Paris alignment criteria within an agreed timeframe, or have operations involving only activities not associated with significant harm. DFIs could use credit lines earmarked for end uses that support Paris Agreement objectives if the $\mathrm{FI}$ is able to comply with phase 1 alignment criteria (phase 1) for subprojects using DFI funds, and if it commits to complying with the requirements for all new investments (phase 2) within a predefined period of a maximum of five years. 
Figure ES1 outlines our proposed approach to using different investment instruments, explaining the circumstances under which various instruments would be allowable.

Under the proposed approach, DFIs could continue to engage with Fls that do not yet have criteria to ensure Paris alignment of new investments, but they would need to do so in ways that minimize the risk of supporting misaligned activities. For Fls that are committed to Paris alignment in principle but that are not yet ready to commit to all concrete steps and the required timeline, DFIs should refrain from providing general purpose loans, equity, guarantees, or earmarked credit lines. With new low- or medium-risk clients, DFIs could use a Paris-aligned special purpose vehicle if the client commits to the principle of Paris alignment. DFIs could also provide targeted technical support to new FI clients that support the principle of alignment.

DFIs would not, however, provide support to Fl clients, new or existing, that have not committed to the principle of Paris alignment or to existing FI clients that are unwilling to commit to a Paris alignment plan. Such a plan would include clear criteria and a timeline for implementation.

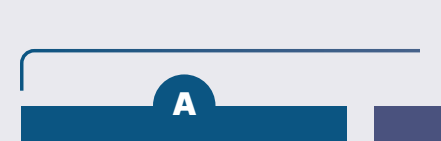

All new FI

investments satisfy

phase 1 PA criteria

$+$

Fl commits to

implementing

phase 2

requirements

within max. 5 years

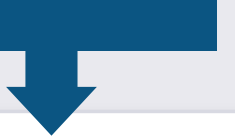

Fl invests in only

non-emitting and

low-risk areas and

does not expand

into areas that

might undermine

Paris goals
General purpose credit lines, guarantees, bonds

Equity investments

- Earmarked credit lines, guarantees, bonds

- Paris-aligned SPVs

- Technical assistance

\section{c}

Fl investments

using DFI funds

satisfy phase 1 PA

criteria

$+$

FI commits to

implementing

phase 2

requirements

within max. 5 years

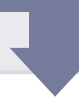

Earmarked

credit lines, guarantees, bonds

- Paris-aligned SPVs

- Technical assistance

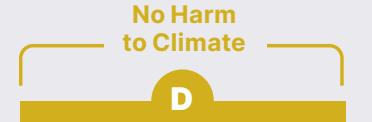

New FI client

commits to Paris

alignment but

is not yet able

to commit to PA

criteria

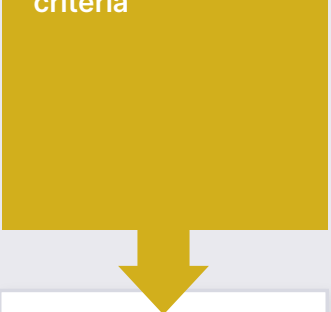

Paris-aligned SPVs for lowand mediumrisk clients

- Technical assistance
Potential Harm to Climate E

FI does not commit to Paris alignment Or

Existing FI client commits to Paris alignment but is not yet able to commit to PA criteria

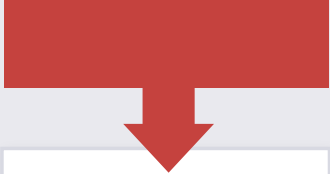

None

Notes: Abbreviations: FI: financial intermediary; PA: Paris alignment; DFI: development finance institution; SPV: special purpose vehicle. Source: Authors. 


\section{Importance of Aligning Development Finance Institutions' Intermediated Investments with the Paris Agreement}

Many development finance institutions (DFIs), including the major multilateral development banks and members of the International Development Finance Club, have committed to aligning with the objectives of the Paris Agreement (ADBG 2017). However, while DFls have presented and piloted approaches for assessing the alignment of new direct investments and have begun to work on criteria for intermediated lending, as of January 2021, none had finalized Paris alignment criteria for their indirect investments through financial intermediaries (FIs). ${ }^{3}$

This paper supports DFIs' Paris alignment efforts by proposing alignment criteria for investments through Fls. It begins with an introduction to Paris alignment and FI investments, followed by an analysis of current financial flows through Fls for 17 DFIs. ${ }^{4}$

Section 2 presents criteria to ensure that investments through Fls are Paris aligned. Section 3 discusses engagement options when interacting with FI clients that commit to Paris alignment but are not yet able to fulfill phase 1 criteria for such alignment. Section 4 looks at engagement options and limitations with clients that are not willing or able to commit to a Paris alignment plan. The paper concludes with a discussion of operational implications for DFIs (Section 5).

\section{Methodology}

The proposed approach is based on a multipronged research process that began with an extensive review of DFIs' current policies, project databases, and annual reports. This baseline research focused on the World Bank Group, including the International Finance Corporation (IFC); the European Investment Bank (EIB); the Asian Development Bank; and the Inter-American Development Bank (IDB); as well as the French bilateral lender Agence Française de Développement (AFD; French Development Agency) and German Kreditanstalt für Wiederaufbau (KfW; Credit Institute for Reconstruction). However, the authors also looked at the policies and current practices of private sector organizations similar to the financial intermediaries that DFIs tend to lend to.

This phase of the research included an analysis of existing $\mathrm{Fl}$ investments using DFI project databases to demonstrate the volume and types of $\mathrm{Fl}$ investments at the different DFIs. It also included a survey of their existing policies and practices related to environmental due diligence and financial intermediaries. Lastly, it drew on evaluations conducted by the banks' independent evaluation bodies and third-party observers on the implementation of due diligence criteria and environmental and social safeguard policies for financial intermediary lending.

The research drew lessons from literature on technologies and activities that align with the global temperature goal, extensive consultations with DFI stakeholders, and the authors' expertise based on past research relating to DFIs and Paris alignment to formulate the proposed approach for aligning $\mathrm{FI}$ investments.

To help define Paris-aligned investment pathways, the paper built on academic and grey literature on technologies, activities, and investment flows that align with the global temperature goal-notably rates of change in sectors consistent with global benchmarks for 2030 and 2050 (Lebling et al. 2020). The recommendations reflect emission reduction potential, availability of mitigation options, maturity of available technologies, lifetime of assets, and other relevant factors. The research and resulting recommendations also benefited from interviews and discussions with DFI shareholders and staff, including from EIB, AFD, IDB, IFC, and $\mathrm{KfW}$, for example, and other stakeholders, as well as written responses to questions. Many interview partners also reviewed and provided feedback on the proposed approach. 


\subsection{Introduction to Paris Alignment and the Role of Governments and DFIs}

Investment decisions made today will determine whether countries can transition to climate-resilient development pathways and net decarbonization by 2050 in line with the Paris Agreement. Recognizing these needs, the signatories of the Paris Agreement pledged in Article 2.1(c) to make "finance flows consistent with a pathway towards low greenhouse gas emissions and climate resilient development" (UNFCCC 2015).

DFIs have significant capacity to help countries shift international finance flows toward low-carbon, climateresilient development. Jointly, public development banks invest more than US\$2 trillion a year (AFD $2020 b)$. Their public mandates call for them to support sustainable development, including decarbonization and climate resilience, which they can do through their own investments and by setting standards that other institutions emulate.

Based on our review of available literature

(Germanwatch and NewClimate Institute 2018; Larsen et al. 2018; I4CE 2019; Dupre et al. 2018), we propose the following definition for a Paris-aligned FI investment:

\footnotetext{
A DFI investment in an Fl can be considered aligned if the following criteria are met: The financial resources are used for purposes that do not undermine climate goals and whenever possible contribute to lowcarbon and climate-resilient development pathways consistent with a 1.5 degrees Celsius $\left({ }^{\circ} \mathrm{C}\right)$ global warming target; and the $\mathrm{Fl}$ is committed to aligning all its financial flows with climate objectives within a specified timeframe. ${ }^{5}$
}

Further, we propose the following definition for a Parisaligned financial institution:

A financial institution (DFl, Fl, or other) is fully Paris aligned if its portfolio exposure, institutional-level criteria, and project-level investment requirements are consistent with limiting global warming to $1.5^{\circ} \mathrm{C}$ and fostering climate resilience and if these criteria are rigorously implemented.

\subsection{Introduction to Financial Intermediary Investments}

With FI projects, DFIs provide loans (also called credit lines), equity investments, debt security, or guarantees to partner financial institutions, which those institutions then use to finance a set of subprojects (EBRD 2018). DFIs can offer credit lines as general purpose loans, meaning the $\mathrm{FI}$ can use the loan to finance any type of subproject. Alternatively, the DFI and FI may agree on specific types of eligible subprojects, such as certain investments in small and medium-sized enterprises (SMEs), road infrastructure, or housing. These are referred to as earmarked, or ring-fenced, loans. Figure 1 illustrates the distinction between direct investments and financial intermediary investments.

Fls include various types of financial institutions, including commercial banks, investment banks, private equity funds, venture capital funds, microfinance institutions, leasing and insurance companies, and national and regional development banks, among others. FI subprojects range from small-scale consumer loans, student loans, and SME projects to larger corporate finance, trade finance, and equity investments, all the way to large infrastructure projects (ADB 2019; EIB 2020b). 


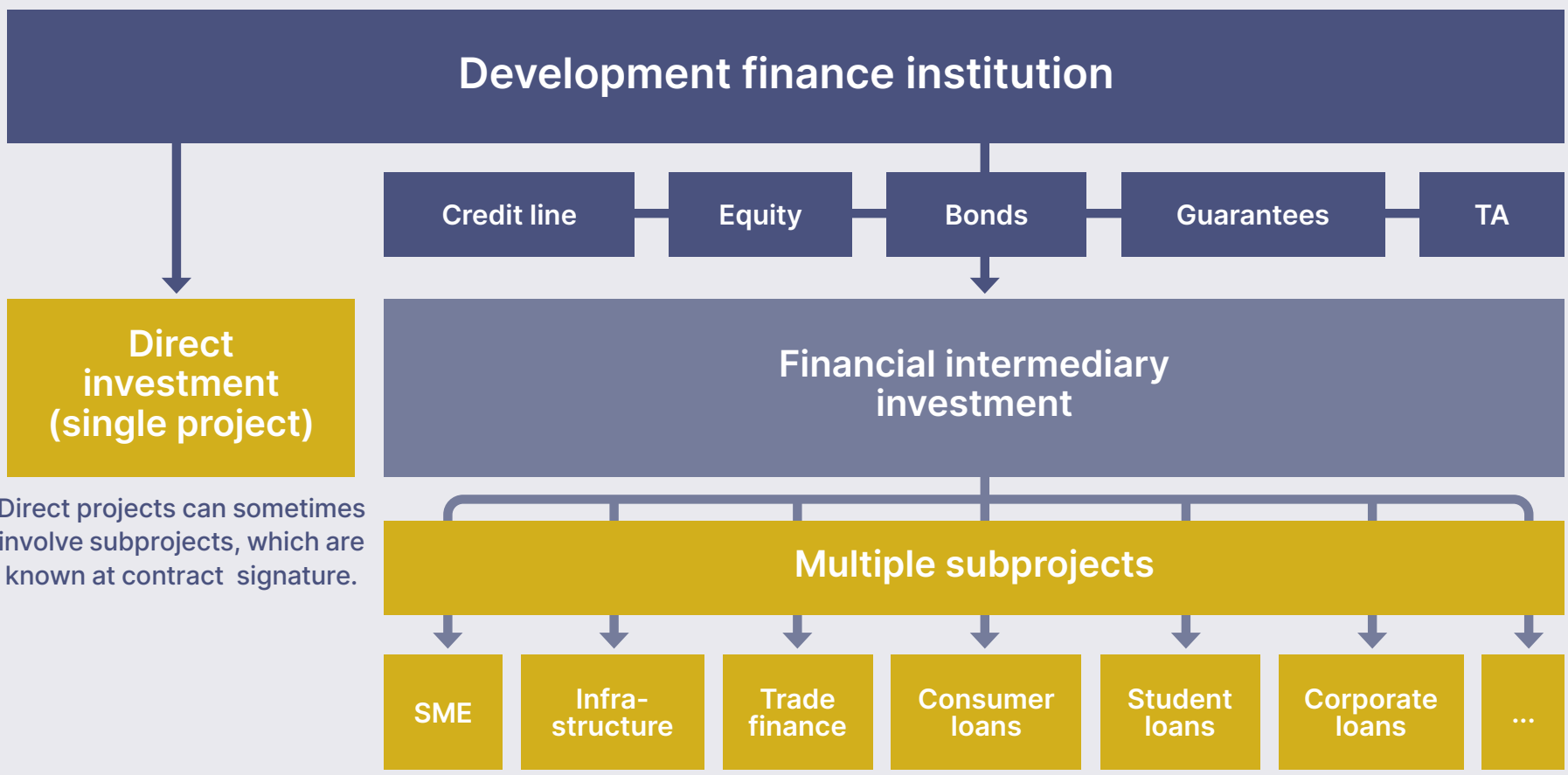

Final subprojects typically unknown at contract signature between development bank and FI.

Note: Abbreviations: TA: technical assistance; SME: small and medium-sized enterprises.

Source: Authors.

\subsection{Current FI Investments}

$\mathrm{Fl}$ investments constitute a significant share of total funding commitments at most of the analyzed DFls or their respective private sector lending arms (Figure 2). They accounted for at least a third of all EIB and European Bank for Reconstruction and Development (EBRD) commitments in 2019. Since Fl investments are often channeled through commercial banks or private equity funds, DFIs with large private sector lending arms tend to channel higher amounts of funding through Fls (from 46 percent to 70 percent in 2019), while those institutions that focus primarily on sovereign lending channels use this funding modality less frequently (from 0 percent to 24 percent in 2019). For example, the World Bank (International Development Association and International Bank for Reconstruction and Development) channeled about 2 percent of its lending through FIs, while its private sector counterpart, IFC, channeled about 63 percent of investments through Fls.
As DFIs respond to the Covid-19 pandemic and associated economic crisis, lending through Fls has continued to be an important tool for DFIs. EBRD's and IFC's shares of FI investments remained stable in $2020^{6}$ compared with 2018 and 2019 (EBRD n.d.; IFC n.d.). The IFC also committed $\$ 6$ billion of its $\$ 8$ billion fast-track Covid-19 support through FIs (IFC 2020a).

Most Fl investments are structured as credit lines and equity investments, followed by guarantees and debt securities or bonds. Credit lines were the most common instrument used in 2019 by the DFIs included in this analysis (Table 1). Equity played a significant role (representing more than 20 percent of Fl investments) at the Asian Infrastructure Investment Bank (AIIB), European Investment Fund (EIF), German Investment Corporation (Deutsche Investitions- und Entwicklungsgesellschaft; DEG), and Proparco. Debt security played a significant role only at AIIB, and guarantees had a share of more than 20 percent at EIF and IDB Invest. 


\section{FIGURE 2 DFI Investments through Fls as a Share of Total DFI Investments (2019)}

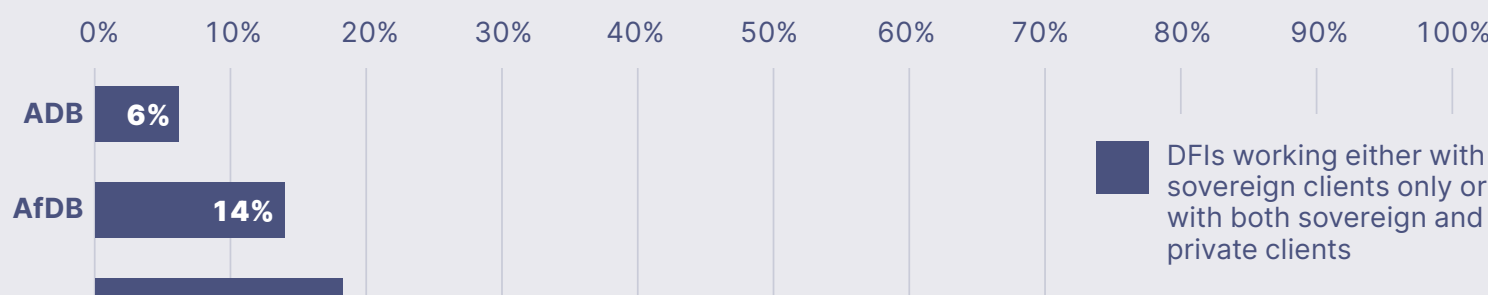

AllB

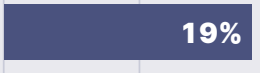

EBRD

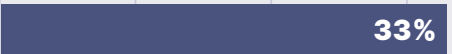

EIB

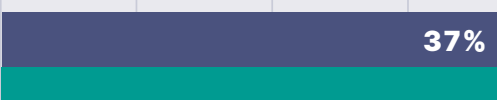

EIF

\section{$37 \%$}

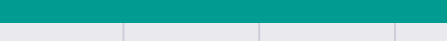

IDB

$6 \%$

IDB Invest

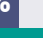

$$
\text { IsDB } 0 \%
$$

ICD

\section{$\mathbf{0} \%$}

NDB

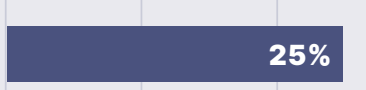

B

$2 \%$

IFC

KfW Development Bank

DEG

$10 \%$
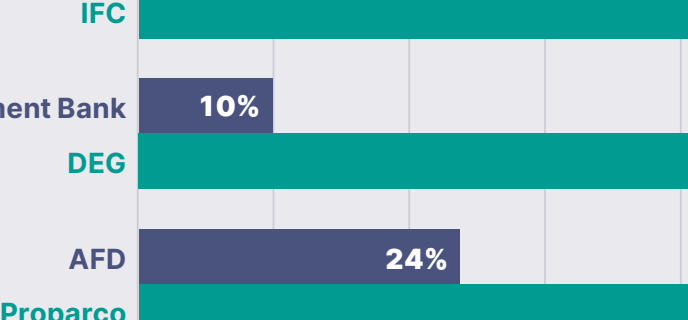

$24 \%$

Proparco

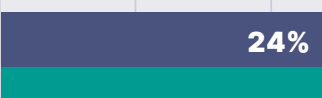

Notes: Numbers are not fully comparable among DFIs as definitions and reporting standards on Fl investments are not harmonized among DFIs. The following definitions were used in line with available information in databases and reports: for ADB, data on the "finance sector" (excluding policy-based loans); for AfDB and ISDB, data on "finance"; for AlIB, data on "financial institutions"; for EBRD, data on "financial institutions and other financial sectors"; for EIB, data on "credit lines, guarantees and equity/quasi-equity"; for EIF, all investments; for IDB, data on "financial markets" (excluding policy-based loans); for IDB Invest, WB, IFC, NDB, AFD, and Proparco, data on "financial intermediary environmental and social category"; for ICD, data on "line of financing and institutional equity"; for KfW Development Bank, data on "banking and financial services"; and for DEG, data on "financial institutions and funds."

Numbers for ISDB refer to IsDB Ordinary Capital Resources.

Numbers for EIB equity and quasi-equity may include financing channeled via national or local authorities.

Abbreviations: DFI: development finance institution; FI: financial intermediary; ADB: Asian Development Bank; AfDB: African Development Bank; AllB: Asian Infrastructure Investment Bank; EBRD: European Bank for Reconstruction and Development; EIB: European Investment Bank; EIF: European Investment Fund; IDB: Inter-American Development Bank; ISDB: Islamic Development Bank; ICD: Islamic Corporation for the Development of the Private Sector; NDB: New Development Bank; WB: World Bank; IFC: International Finance Corporation; KfW: Kreditanstalt für Wiederaufbau (Credit Institute for Reconstruction); DEG: Deutsche Investitions- und Entwicklungsgesellschaft (German Investment Corporation); AFD: Agence Française de Développement (French Development Agency). 


\begin{tabular}{|c|c|c|c|c|c|c|c|c|c|c|c|c|}
\hline & ADB & AllB & EBRD & ElB & EIF & IDB & $\begin{array}{r}\text { IDB } \\
\text { Invest }\end{array}$ & NDB & WB & IFC & DEG & Proparco \\
\hline Credit lines & $66 \%$ & $60 \%$ & $47 \%$ & $86 \%$ & $0.3 \%$ & $99 \%$ & $72 \%$ & $93 \%$ & $100 \%$ & $84 \%$ & $56 \%$ & $77 \%$ \\
\hline Equity & $18 \%$ & $34 \%$ & $8 \%$ & $7 \%$ & $33 \%$ & - & $4 \%$ & $7 \%$ & - & $9 \%$ & $30 \%$ & $21 \%$ \\
\hline $\begin{array}{l}\text { Debt security/ } \\
\text { Bonds }\end{array}$ & $16 \%$ & $6 \%$ & $42 \%$ & - & - & - & $3 \%$ & - & - & - & $7 \%$ & - \\
\hline Guarantees & - & - & $3 \%$ & $8 \%$ & $67 \%$ & - & $21 \%$ & - & - & $7 \%$ & - & $2 \%$ \\
\hline Othera & - & - & - & - & - & $1 \%$ & - & - & - & - & $7 \%$ & - \\
\hline
\end{tabular}

Notes: Numbers are not fully comparable among DFls as definitions and reporting standards on Fl investments are not harmonized among DFls. For example, some banks report separately on the share of technical assistance in Fl investments, while others do not.

a. "Other" refers to technical cooperation and investment grants for IDB and no info for DEG.

No public information for the FI project instrument split is available for AfDB, AFD, IsDB, ICD, or KfW.

Instrument shares by DFI may not add up to 100 percent due to rounding.

Abbreviations: DFI: development finance institution; FI: financial intermediary; ABD: Asian Development Bank; AllB: Asian Infrastructure Investment Bank; EBRD: European Bank for Reconstruction and Development; EIB: European Investment Bank; ElF: European Investment Fund; IDB: InterAmerican Development Bank; NDB: New Development Bank; WB: World Bank; IFC: International Finance Corporation; DEG: Deutsche Investitions- und Entwicklungsgesellschaft (German Investment Corporation); AfDB: African Development Bank; AFD: Agence Française de Développement (French Development Agency); IsDB: Islamic Development Bank; ICD: Islamic Corporation for the Development of the Private Sector; KfW: Kreditanstalt für Wiederaufbau (Credit Institute for Reconstruction).

Sources: ADB n.d.; AIIB n.d.; DEG n.d.; EBRD n.d.; EIB n.d., 2020a, 2020c; IDB n.d.; IDB Invest n.d.; IFC n.d.; KfW n.d.; NDB n.d.; Proparco n.d.; World Bank n.d.

\subsection{Benefits and Risks Associated with Investments through Fls}

DFIs report several potential benefits to investing through Fls. First, by investing through local financial institutions, DFIs can help strengthen domestic financial markets and promote access to financial services. Second, earmarked credit lines can be used to support specific topics such as gender equality and improved environmental and social risk management. Third, FI investments allow DFIs to support a larger number of smaller projects than they could efficiently do on their own (Curmally et al. 2005). Investing through Fls also expands DFIs' subproject sourcing capabilities, allowing them to invest greater volumes and in broader geographies.

Investing through Fls is not without challenges and risks. DFI approval processes for $\mathrm{Fl}$ investments are similar to their processes for approving direct lending projects. DFIs outline the purpose, target group, and financing modality of the investment in project appraisal documents and in their contracts with Fls. The main difference between direct investments and investments through Fls is that, in the case of Fls, individual subprojects are not typically known at the time of approval. Generally, after an Fl investment is approved, the financial and technical responsibility for subproject 
assessment, approval, and management lies with the FI (Curmally et al. 2005). In some institutions, DFIs require Fls to refer subprojects with significant environmental and social risks to them for final approval (ADB 2009; IDB 2020; AllB 2020).

Longer investment chains can make it more difficult for DFIs to track the final impact of their investments. Investigations by nongovernmental organizations (NGOs) and DFI evaluation units have repeatedly found cases where required environmental and social standards had not been implemented in subprojects financed by FI clients. Ring-fenced money sometimes supports unintended purposes, and DFIs have been unaware of the client's harmful investments using funds not provided by the DFI (Oxfam 2020; BIC Europe and SOMO 2018; CAO 2012). In addition, client confidentiality provisions have resulted in less transparency concerning the use of funds channeled through Fls compared with the transparency of direct investment projects (Oxfam 2018).

These challenges mean that DFls need to implement effective, transparent systems to ensure that subprojects financed through Fls are aligned with the DFIs' development mandates and standards, including their commitments to Paris alignment, given their responsibility for the impacts of their development finance.

\section{Framework for Paris-Aligned Intermediated Finance}

We propose a Paris alignment framework that DFIs could use to align their FI investments with the Paris Agreement. Our approach is informed by several guiding principles. These principles suggest that the criteria DFIs apply should be

robust enough to ensure that FI lending adheres to Paris Agreement goals;

- tailored to risks posed by the specific $\mathrm{FI}$ investment, based on the sectors the $\mathrm{Fl}$ invests in and the financial instrument used;

- practical to ensure Fls with varying levels of capacity and expertise can implement them; and

- more ambitious over a defined timeline, as Fls build up capacity and criteria to comply.

The proposed framework includes criteria under four pillars relevant to Paris alignment: mitigation, adaptation, governance, and transparency. To ensure alignment, Fls would need to satisfy requirements within each of these areas. For mitigation and adaptation, we propose criteria that Fls would apply at the subproject level. For governance and transparency, we propose criteria relevant to the $\mathrm{FI}$ institution as a whole (Figure 3 ). The approach also describes the responsibilities of DFIs to engage with Fls and ensure compliance. 


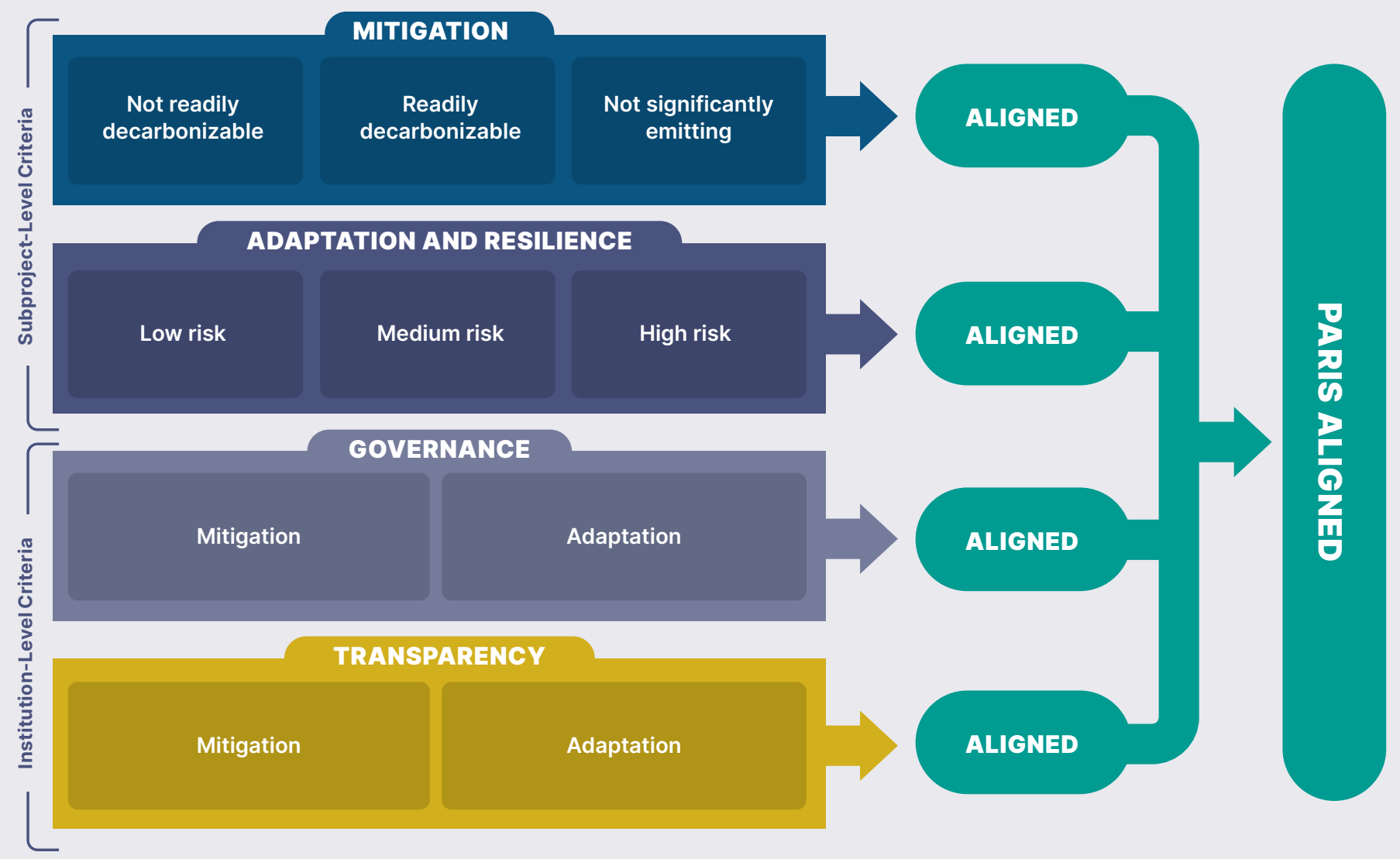

Source: Authors.

\subsection{A Phased, Risk-Based Approach for Fls to Reach Full Alignment over Time}

Recognizing that Fls today have different levels of capacity to implement Paris alignment activities, we propose a phased approach whereby DFIs would require Fls to meet certain requirements in phase 1 , when the contract between the DFI and FI is being approved, and additional requirements in phase 2 . This approach aims to balance the need for robust criteria that minimize the risk of misaligned investments with that of finding a workable solution for capacity-constrained Fls.

\section{Phase 1}

In phase 1, Fls would need to meet several requirements (detailed in the subsections that follow) related to mitigation, adaptation, governance, and transparency to ensure that financed subprojects are Paris aligned. If capacity is insufficient, the DFI would work with the $\mathrm{FI}$ to implement relevant activities and develop the capacity to do so on its own. In phase 1, the DFI could ring-fence funds to reduce the risk that DFI investments undermine climate goals (such ring-fencing would be avoided in phase 2). 


\section{Proactive DFI support for Fls}

Before contract approval, under our proposed framework, the DFI would assess and disclose whether the FI client has the capacity and systems in place to ensure that its investments are Paris aligned.

Often, Fls in countries most in need of support have the least capacity to implement climate and environmental structures and processes. If Fls are willing to commit to Paris alignment but do not have the necessary capacity to meet the phase 1 requirements, DFls would work directly with FI clients to assess, approve, and monitor subprojects. Some Fls will need more support in aligning with mitigation goals, others with adaptation and resilience, and still others in reporting and disclosure. Many will need help to varying degrees in all these areas. To receive this support, Fls should commit to a plan to develop the necessary in-house capacity before phase 2.

\section{Requirements for funding types based on Paris alignment status}

In phase 1, the DFI could earmark funds to further reduce the risk that financial support will go to misaligned investments.

In cases where funding is not earmarked, there is greater risk that DFI funding will support misaligned activities. General purpose loans, general guarantees, and equity investments are not earmarked for subprojects in specific sectors or types of activities. While these instruments offer financial flexibility to the $\mathrm{Fl}$, it can be difficult for the DFI to follow the impact of its investments in these cases. As a result, to manage the increased risk, a DFI providing general purpose loans, general guarantees, or equity investments will need to impose requirements for all $\mathrm{FI}$ operations in phase 1, rather than applying Paris alignment criteria only to subprojects financed using DFI funds.

The risk that DFI funds are used to support activities that do not align with climate goals is smaller when DFIs earmark funds for specific types of activities. In phase 1 , such earmarking allows the DFI and FI to focus on ensuring that these investments are Paris aligned, while building up systems to help the FI move all investments toward Paris alignment in the near future. Figure 4 outlines the circumstances under which different types of financial instruments can be used.

\section{Phase 2}

The second phase of implementation would require Fls to implement their own systems for Paris alignment with reduced support from DFIs. It would also require these organizations to apply these systems to their entire investment portfolios.

Earmarking loans for subprojects in specific sectors can reduce the risk that DFI funds will directly benefit misaligned activities but it does not fully eliminate that risk. On the one hand, poor design or enforcement of ring-fencing provisions can lead to DFI funds financing unintended subprojects (BIC Europe and SOMO 2018). On the other hand, even earmarked investments can free up capital to invest in misaligned projects by decreasing an Fl's overall weighted average cost of capital. For instance, most green bonds actually refinance the whole balance sheet of the issuer (Dupre et al. 2018). An internal ElB evaluation also found that Fls are picking up the best subprojects to report back to the EIB, but that they still use the credit line for general liquidity (EIB 2017). Similarly, NGO reports have highlighted cases where recipients of IFC green credit lines have concurrently continued significant financing for coal (Inclusive Development International et al. 2018).

For these reasons, in phase 2, Fls would be required to ensure Paris alignment of activities beyond those ring-fenced by the DFI.

The time horizon for Fls to implement requirements of phase 2 can be determined depending on how far the $\mathrm{Fl}$ is from meeting these requirements but should not exceed a clearly set maximum. For new Fl investments in 2021, we propose a maximum of five years as a reasonable time horizon for Fls to develop and implement phase 2 criteria. We propose that for new Fl investments in 2025 the time horizon should be decreased to three years and in 2030 to one year (Table 2).

Figure 5 provides a high-level overview of our proposed FI Paris alignment approach. The following subsections explain each pillar of our framework in more detail. 


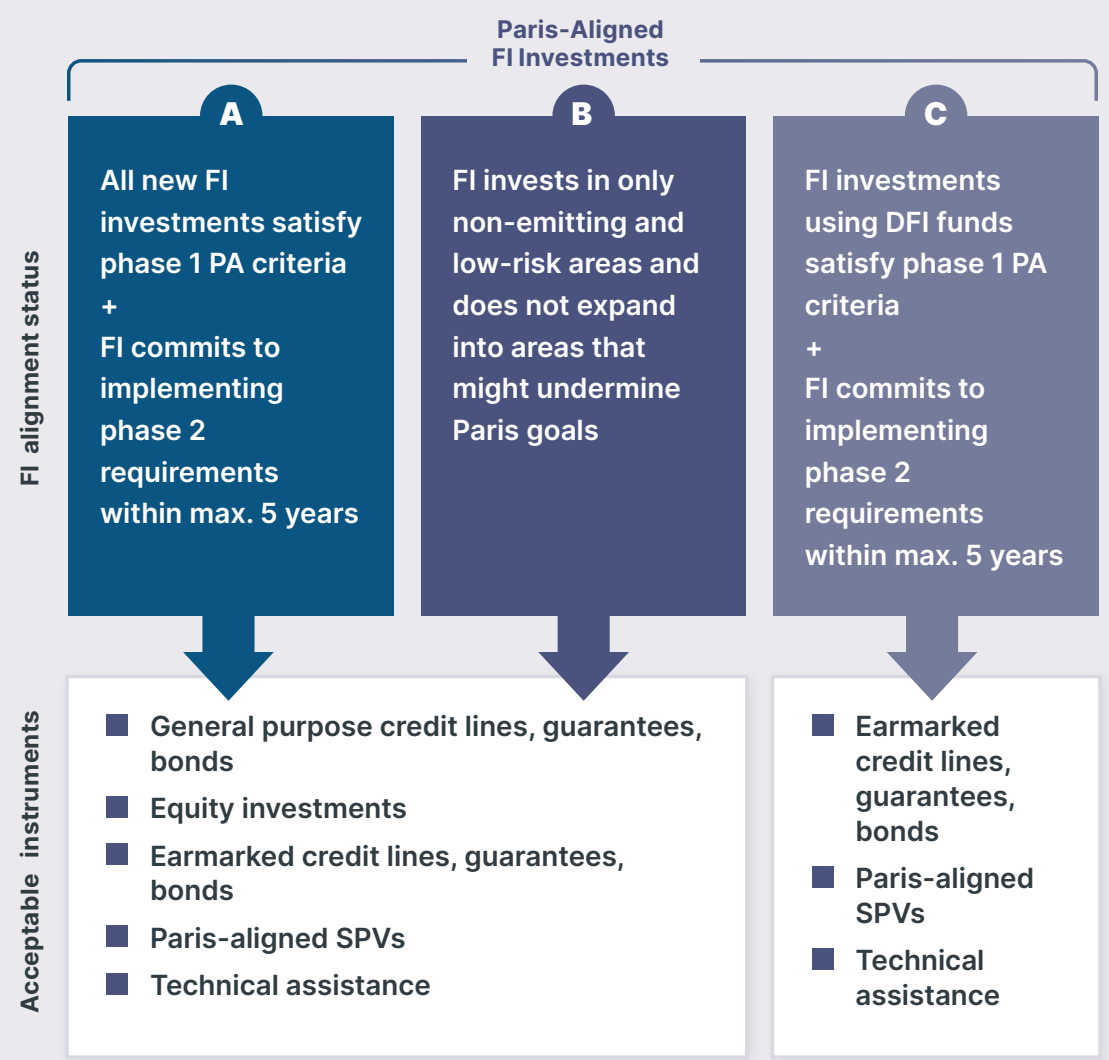

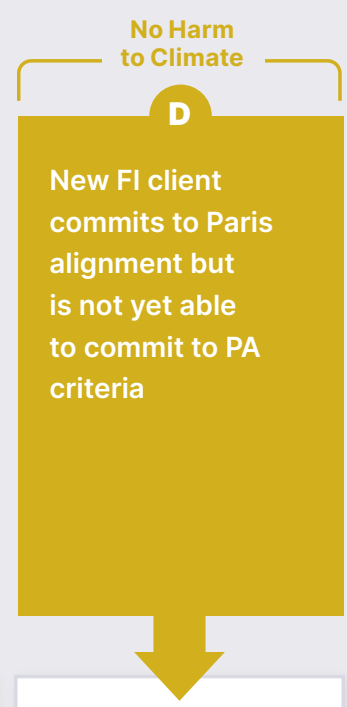

Paris-aligned SPVs for lowand mediumrisk clients

- Technical assistance
Potential Harm

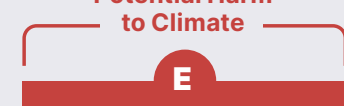

FI does not commit

to Paris alignment

Or

Existing FI client

commits to Paris

alignment but

is not yet able

to commit to PA

criteria

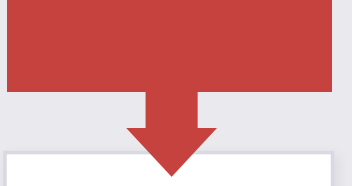

none

Notes: Abbreviations: FI: financial intermediary; PA: Paris alignment; DFI: development finance institution; SPV: special purpose vehicle. Source: Authors.

\section{TABLE 2 The Time Frame to Implement All Paris Alignment Requirements Should Decrease over Time}

\begin{tabular}{lll} 
& Phase 1 Requirements for Fls & Phase 2 Requirements for Fls \\
\hline 2021 & Immediately & Within a maximum of 5 years \\
\hline 2025 & Immediately & Within a maximum of 3 years \\
\hline 2030 & immediately & Within a maximum of 1 year \\
\hline
\end{tabular}

Note: Abbreviation: Fl: financial intermediary.

Source: Authors. 


\section{FIGURE 5 Overview of Proposed Paris Alignment Approach for Intermediated Finance}

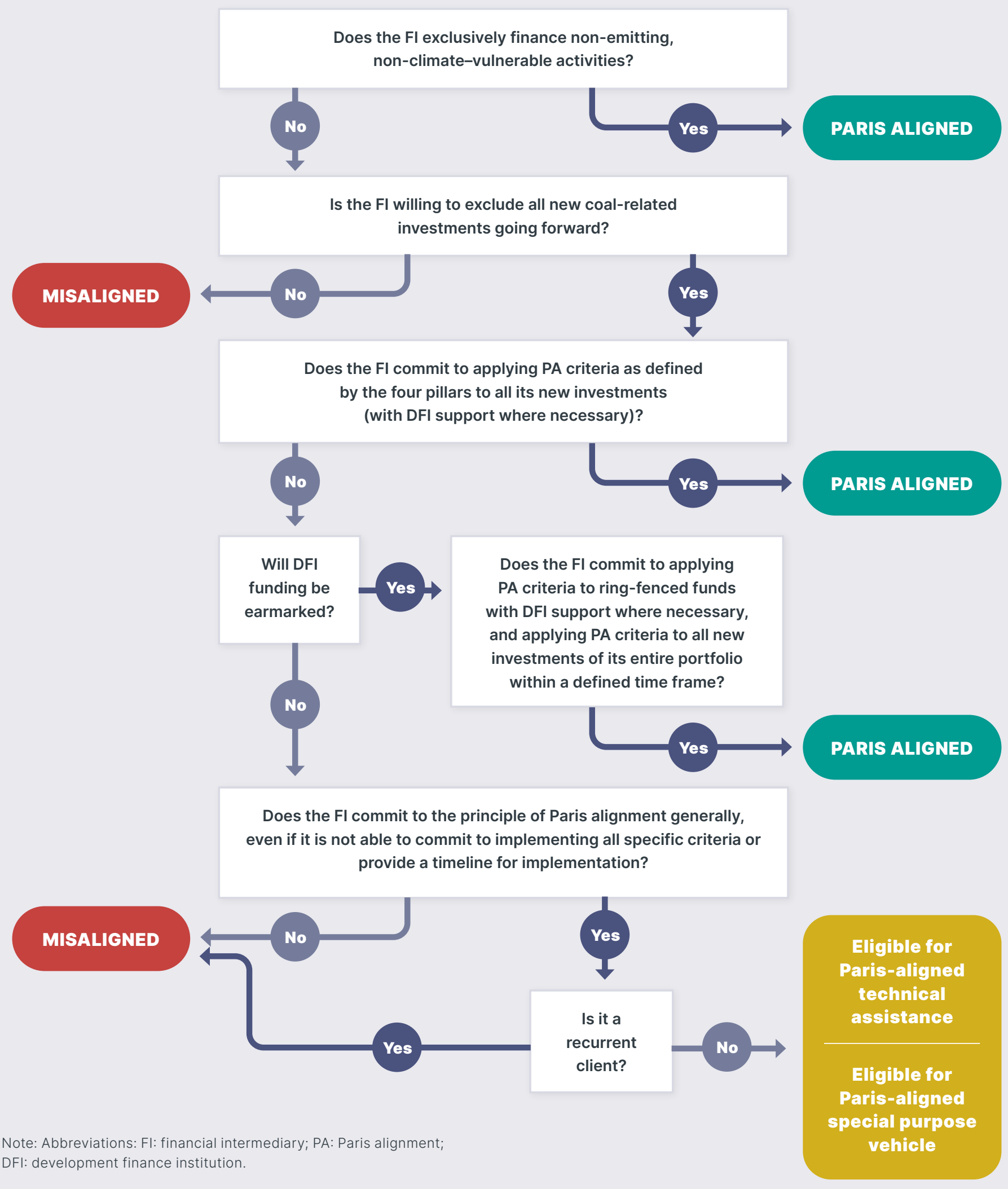




\subsection{Pillar One: Alignment with the Mitigation Goal Requires an Assessment of the Fl's Current Portfolio, Trends, and Application of Criteria for New Subproject Lending}

Different Fls pose different risks with respect to the Paris Agreement's mitigation goal. For instance, Fls may be exclusively active in sectors without significant emissions, such as student loans or private consumer loans. On the other hand, an FI that is heavily invested in the fossil fuel industry, internal combustion engine vehicles, or unsustainable resource exploitation poses considerably higher risk of undermining alignment efforts. The required alignment criteria will thus depend on the sectors an FI operates in, as reflected by its portfolio.

We propose that DFIs review FI portfolios to assess exposure to high-risk sectors. The review would cover three sector categories based on emissions and decarbonization potential: sectors without significant emissions, readily decarbonizable sectors, and sectors that cannot be readily decarbonized (Table 3 ). DFIs would assess both current $\mathrm{Fl}$ investments and new business strategies. Where necessary due to data constraints, the DFIs could start with a high-level sectoral assessment and build upon this over time. DFIs would then institute different requirements for Fls based on the findings of this assessment.

\subsubsection{Sectors without significant emissions}

Activities without significant emissions are those that do not meaningfully produce scope 1, 2, or 3 emissions (WBCSD and WRI 2015). Examples include student loans and certain small consumer loans (not including car loans or mortgage lending). The AFD, for example, uses a threshold of less than 10,000 tons of carbon dioxide per year ( $\mathrm{tCO}_{2} /$ year) for an activity to be counted as not significantly emitting (AFD 2017).

An Fl that exclusively engages in these types of activities and has no plans to expand its operations into the other sector categories can be considered aligned with the Paris Agreement's mitigation goal. As a result, it would not need to apply any additional criteria to assess the mitigation alignment of its subprojects under our proposed approach.

\subsubsection{Sectors that are readily decarbonized}

Some high-emitting sectors can be readily decarbonized by substituting fossil fuel usage with renewable electricity. These include the power sector, new buildings, light duty vehicles, and public transport. If the $\mathrm{Fl}$ is active or likely to become active in these sectors, we propose using Paris-aligned exclusion lists to guide DFI engagement with the FI. Exclusion lists (sometimes referred to as negative lists) are tools that many DFIs already use in their FI operations to rule out investments in activities that conflict with their

TABLE 3 Three Sector Groupings to Categorize an Fl's Portfolio Based on Emissions Level and Decarbonization Potential 
environmental and social standards. DFIs can draw on an ample body of literature in developing Paris-aligned exclusion lists (see, for example, Germanwatch and NewClimate Institute 2018; Climate Action Tracker 2020; Kuramochi et al. 2018, 2016; Lebling et al. 2020). Importantly, those lists would need to be updated, for example, every five years, to account for decarbonization pathways and as new data and technologies emerge.

Following the proposed two-phased approach, the exclusion list would apply to earmarked funds in phase 1 and to all $\mathrm{Fl}$ investments in phase 2 . There would be two exceptions to this:

1. New coal-related energy investments. Given the urgency of phasing out coal infrastructure, Fls should be deemed ineligible for investments (including earmarked funds) if they simultaneously invest in any coal-related infrastructure.

2. General purpose financing and equity investments. Where these instruments are used, the exclusion list would apply to the Fl's entire new investment portfolio, as described in Section 2.1 (see Figure 6).

\subsubsection{Sectors that cannot be readily decarbonized}

\section{Benchmarks}

Some high-emitting sectors are not readily decarbonized with widely available technologies. These include cement, steel, plastics, agriculture, aviation, and some industrial processes (ETC 2018; Ahman n.d.). If the portfolio analysis shows that the $\mathrm{Fl}$ is active, or has plans to become active, in these sectors, then the DFI would need to require the FI to apply sector-specific subproject-level criteria. Best available technology (BAT) standards or other benchmarks can be useful in these carbon-intensive industries. Activities that deploy technologies that exceed established emission benchmarks or that do not meet BAT standards could be classified as misaligned.
Applied benchmarks should reflect the objective to limit global warming to $1.5^{\circ} \mathrm{C}$. For example, the proposed EU Taxonomy (EU TEGSF 2019) provides benchmarks for sectors that are not readily decarbonized that reflect greenhouse gas ( $\mathrm{GHG}$ ) levels that correspond to the best performance in the industry or sector; do not hamper the development and deployment of low-carbon alternatives; and do not lead to a carbon lock-in inconsistent with the $1.5^{\circ} \mathrm{C}$ target, considering the asset's lifetime. Similarly, the Climate Action Tracker (2020) provides benchmarks in line with the $1.5^{\circ} \mathrm{C}$ target for different industries in different countries (EU TEGSF 2019; Climate Action Tracker 2020). While existing standards are based on currently available technology, they can provide a safeguard against locking in highemission investments. However, standards would need to be reviewed on a regular basis (e.g., every five years) to reflect technological developments and be consistent with long-term decarbonization.

\section{Sustainability Certification}

BAT standards and other benchmarks are not available or feasible for all sectors. For example, it is particularly challenging for the agriculture sector to meet them partly because of the limited options available to eliminate nitrous oxide and methane emissions (Arneth et al. 2019; Lebling et al. 2020). Paris alignment in the agriculture and land use sectors implies protection of high carbon stock ecosystems, such as rainforests, peatlands, and coastal wetlands, as well as a shift toward agricultural practices that reduce emissions per unit of food produced. The specific practices required depend on the agricultural activity but include measures to reduce methane emissions from livestock (especially cattle), reduce nitrous oxide emissions from the application of synthetic fertilizers, and minimize soil carbon loss (EU TEGSF 2019). Product-specific benchmarks are challenging in this sector due to its dispersed nature, the variety of products and commodities involved, and the prevalence of contextspecific conditions. Leading rigorous sustainability certification schemes may offer a practical alternative to minimize risk of misalignment. ${ }^{7}$ 


\section{Summary of Subproject-Level Mitigation Requirements}

Figure 6 summarizes the mitigation requirements for Fls. In the first phase, Fls active in sectors with significant GHG emissions should implement the mitigation criteria described above. In the second phase, Fls should implement transition risk assessments. ${ }^{8}$ In the case of earmarked, or ring-fenced, investments, in phase 1, mitigation criteria would apply only to DFI funds; in phase 2, they would apply to all of the Fl's new investments. In the case of general purpose lending or guarantees and equity investments, criteria would apply to all new investments in phase 1. DFIs would need to monitor implementation of these requirements (see Section 2.6). Additionally, as Fls adopt investment criteria, DFIs would scrutinize those criteria to ensure they are robust.

\section{FIGURE 6}

Decision Tree for Assessing Compliance with Mitigation-Related Alignment Criteria

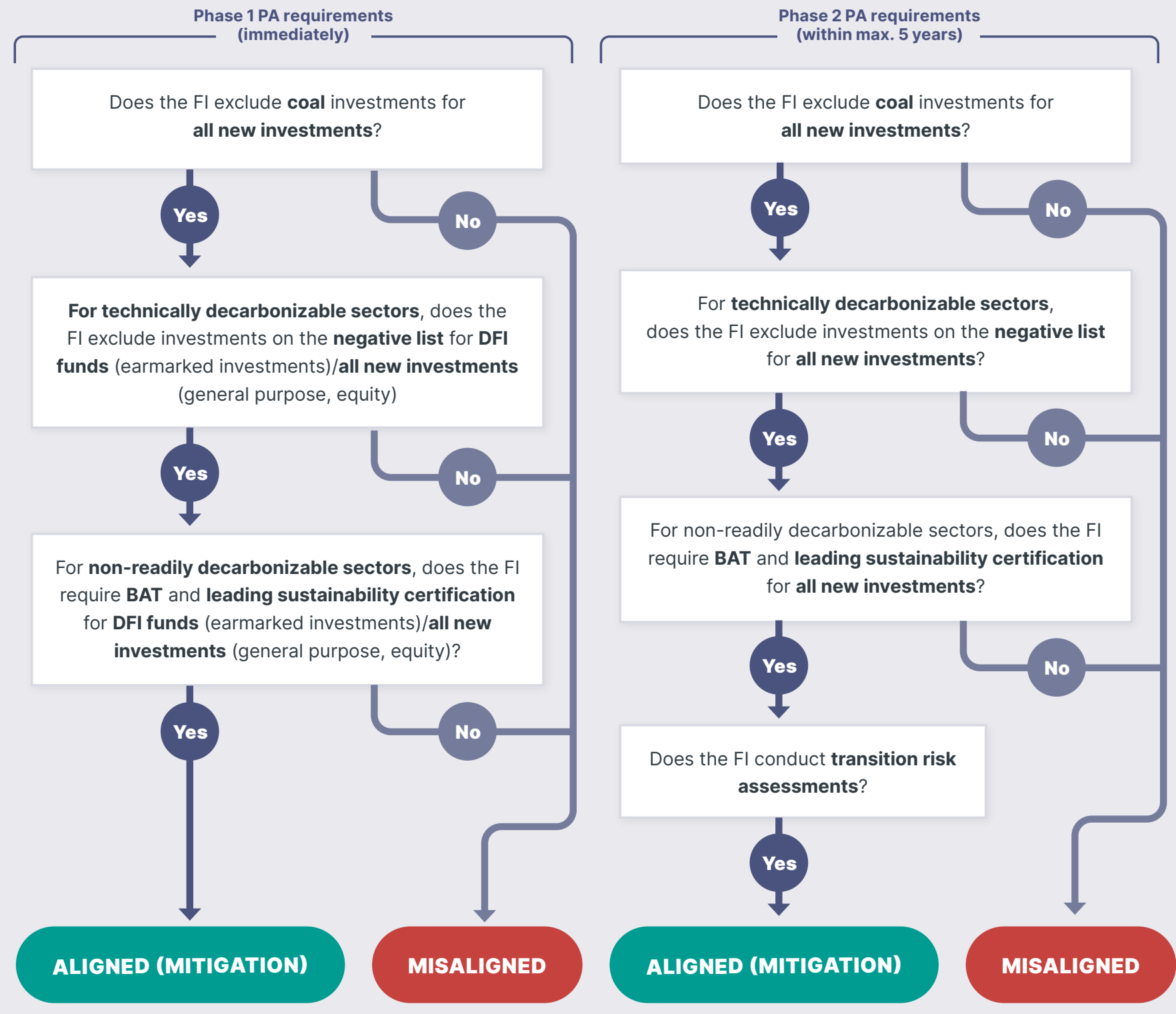

Note: Abbreviations: PA: Paris alignment; FI: financial intermediary; DFI: development finance institution; BAT: best available technology. 


\subsection{Pillar Two: Alignment with Adaptation Goals Requires Fls to Assess and Manage the Physical Climate Risks of Their Investments}

Most DFIs screen new direct investments for climaterelated physical risks (Larsen et al. 2018). If initial screening identifies high levels of risk, DFIs often conduct additional, more in-depth risk assessments and incorporate resilience measures into the project design based on those assessments. We recommend that DFIs support Fls in adopting similar processes to ensure alignment with adaptation objectives. As with other parts of this framework, this process would be implemented in two phases.

In phase 1, DFIs would require Fls to screen subprojects using DFI funding (or all new projects in the case of general purpose lending) for climate-related risks and categorize them as presenting high, medium, or low physical climate risk. DFIs use a range of tools for risk screening, from bespoke tools (e.g., the World Bank's Climate and Disaster Risk Screening Tools) to commercially available off-the-shelf software (e.g., Acclimatise Aware used by the Islamic Development Bank; see Acclimatise n.d. and Westphal and Sidner 2020). DFIs could provide guidance to FIs on how to use similar approaches to categorize investments based on the sector, location, and projected climate conditions.

Under the proposed approach, in phase 1, if initial risk screening categorizes a subproject as high or medium risk, an additional, more comprehensive risk assessment would be needed. In such a case, the FI could either conduct further vulnerability assessments and incorporate appropriate resilience measures into project design if they can show they have the requisite tools and capacity to do so; allow the DFI to conduct the risk assessment and spell out required changes; or decline to finance such subprojects.
In phase 2, Fls would begin to screen all new investments for climate-related risks and conduct more detailed risk assessments for projects categorized as high or medium risk. Additionally, they would no longer rely on DFIs to conduct these more thorough vulnerability assessments and propose resilience options; instead, having used the intervening period to build their own capacity, they would carry out such assessments on their own (Figure 7).

Ideally, risk assessments for medium- and high-risk projects would include detailed, quantitative calculations of risks. In some instances, the size or design of the project, coupled with data gaps and resource constraints, may make full qualitative assessments impossible or unnecessary. Quantitative assessments can, however, make it easier to include climate risks and adaptation options into the economic or financial analysis of the project. Examples of quantitative indicators include the percent reduction in crop yields likely to result from projected precipitation and temperature changes or the percent decline in streamflow likely to result from precipitation variability. There are several best practice principles on quantitative risk assessment. In particular, quantitative risk assessments should do the following:

1. Include short- (10 years), medium- (20-30 years), and long-term (30-50 years) climate risks

2. Explore a range of emission scenarios and climate models

3. Consider uncertainty and, where possible, present impacts in terms of probabilities (Westphal and Sidner 2020)

Given uncertainties, the selection of adaptation options should include safety margins and low- or no-regret options and reflect the use of sensitivity analysis or robust decision-making approaches. DFIs could consider offering technical assistance to their Fls on scenario analysis and adaptation planning. They could also support FI capacity to identify and incorporate resilience measures into project design, and ensure $\mathrm{FI}$ compliance with these requirements through monitoring and oversight, including audits, on a sample basis. 

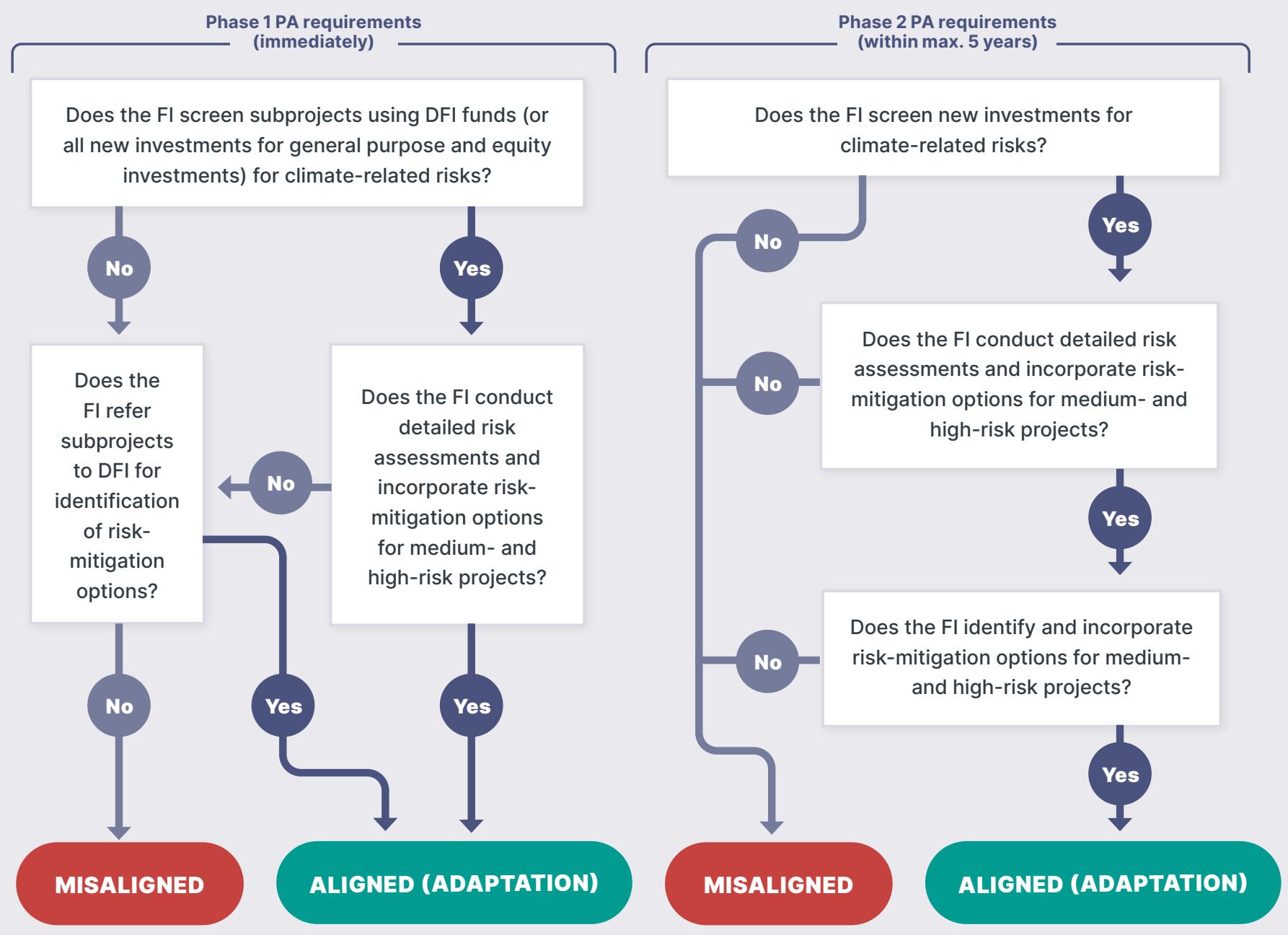

Note: Abbreviations: PA: Paris alignment; FI: financial intermediary; DFI: development finance institution. 


\subsection{Pillar Three: Paris-Aligned Governance and Strategies Require Assessment of the Fl's Commitment, Targets, Processes, and Capacity to Align Its Financial Flows with the Paris Agreement}

To ensure that subprojects are aligned with the mitigation and adaptation goals of the Paris agreement, DFIs also need to make certain that Fls have the commitment, capacity, and corresponding governance processes in place to implement the Paris alignment criteria. We recommend that DFIs engage with their $\mathrm{FI}$ clients in phase 1 to build the necessary capacity and governance structures.

Development banks can build on existing experience in requesting and assessing the environmental and social (E\&S) policies and governance systems of Fls. For example, some DFIs already assess whether the $\mathrm{Fl}$ is committed to and has the capacity to implement robust environmental and social safeguards to the projects they finance. The IFC requires that the $\mathrm{FI}$ has or develops an E\&S policy. The IFC further requires that the Fl's senior management and board endorse this policy and commit to "develop[ing] and maintain[ing] the necessary internal capacity and structure for its implementation." Additionally, the IFC requires the FI to actively communicate the E\&S policy to all employees (IFC 2018)-though not to the public. Best practice would require public disclosure of the Fl's policies, as well as an independent evaluation of adherence to the policy (see Section 2.6). Similar requirements should hold for the implementation of the Fl's Paris alignment strategy. Such requirements are meaningful only to the extent that they are implemented thoroughly and accountability on these requirements is met through reporting. Therefore, we propose assessing commitments and capacities in phase 1 and assessing implementation of those commitments in phase 2 .

We recommend that DFI project managers use the following questions to assess whether the $\mathrm{FI}$ has the necessary governance processes in place (see also Figure 8). Under our proposed approach, Fls would explain how they satisfy each in project proposals. ${ }^{9}$

\section{Phase 1}

First, is there high-level support within the FI for aligning the financial institution with the Paris Agreement goals? To demonstrate high-level support, the Fl's senior management or board would commit to Paris alignment including to mitigation, adaptation, and transparency criteria (see Sections 2.2, 2.3, and 2.5), a timeline for implementation of all criteria, and a climate finance target. In line with our definition of a Paris-aligned $\mathrm{FI}$ investment (see Section 1.1), the implementation of Paris alignment criteria would ensure that subprojects do not undermine the Paris climate goals. Climate finance targets typically lead to an increase in climatepositive investments over time and thus help incentivize subprojects with climate co-benefits wherever possible.

Second, has the Fl's senior management or board committed to developing and maintaining the climate expertise, capacity, and organizational structures necessary to assess the Paris alignment of individual subprojects? Each FI would commit to employing at least one climate expert or a climate team to assess all projects before approval. This would include consulting with project managers (i.e., credit or investment officers) on climate issues and developing processes that ensure that each subproject is assessed for mitigation and adaptation criteria (see Sections 2.2 and 2.3).

Assessing the governance structures and $\mathrm{FI}$ commitments by DFIs would identify where the FI stands in terms of capacity and organizational processes, as well as the steps and resources needed for the FI to implement Paris alignment criteria. Such assessments would be made public to ensure a minimum level of disclosure and transparency.

The DFI and FI would agree on a binding timeline for when the FI will implement the Paris alignment commitments, including respective capacity needs and organizational structures. This would be completed by phase 2 and take a maximum of five years. 


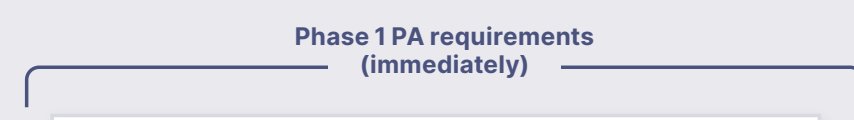

Does Fl senior management or board commit to aligning the FI with Paris goals, including to a climate finance target and subproject-level PA assessments

(i.e., mitigation and adaptation requirements)?

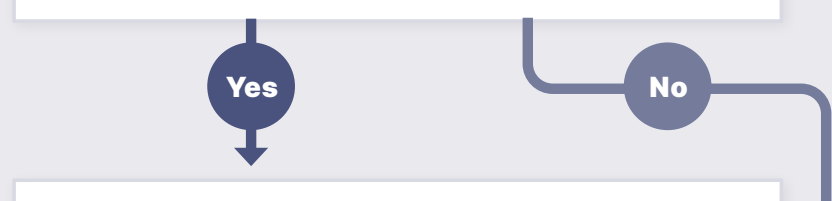

Does FI senior management or board commit to developing and maintaining the capacity and organizational structures needed to conduct subproject-level PA assessments?

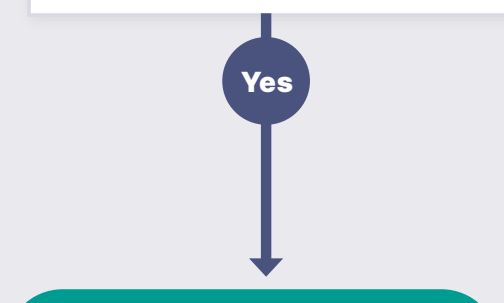

\section{ALIGNED (GOVERNANCE)}

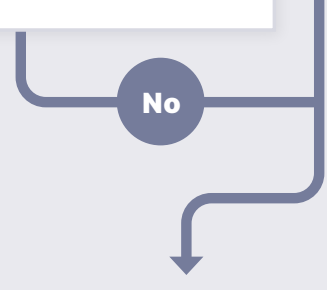

MISALIGNED
Phase 2 PA requirements

(within max. 5 years)

Does the FI remain committed to PA?

Has the FI reached or made significant progress

toward a climate finance target and implementing all PA criteria?
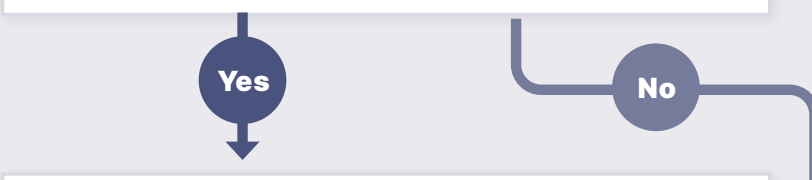

Does the FI have the capacity and

organizational structures needed to conduct

subproject-level PA assessments?
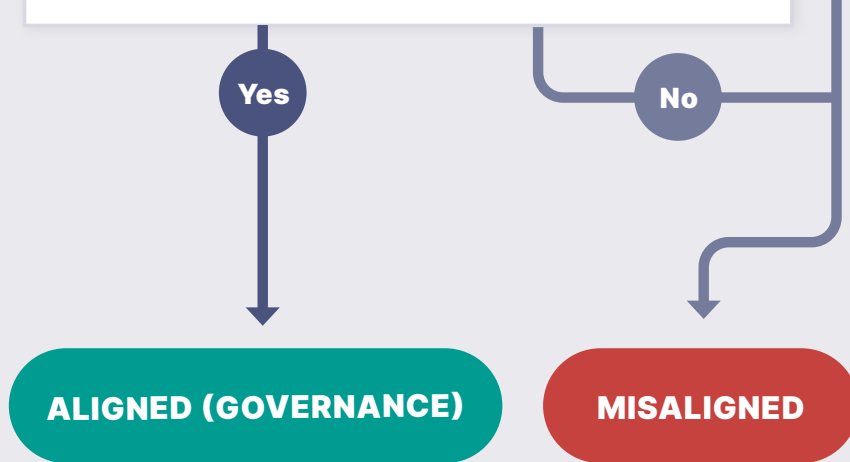

MISALIGNED

Source: Authors.

\section{Phase 2}

Under the proposed approach, senior FI management or the FI board would have endorsed a Paris alignment strategy, including the Fl's Paris alignment approach, and assumed oversight and responsibility for ensuring all its new investments are Paris aligned by phase 2 . The FI would also demonstrate that it has reached or made significant progress on its climate finance target. If the FI has still not implemented its commitments by this time, the DFI would limit its engagement or consider discontinuing the lending relationship (see Section 4).

\subsubsection{Exceptions and special cases}

Fls that engage only in projects without significant emissions and that are unlikely to be vulnerable to climate change pose significantly lower risks of misalignment. DFIs could thus consider waiving specific governance requirements for these particularly low-risk FI clients.

FIs that lend exclusively to SMEs with scope 1, 2, and 3 emissions under $10,000 \mathrm{tCO}_{2} /$ year ${ }^{10}$ pose minimal risk of investing in activities that are misaligned with the mitigation goal. However, its subprojects may be misaligned with adaptation objectives. DFIs could thus consider waiving those institutional requirements that are specific to mitigation, while still requiring adaptationand resilience-related requirements. Exceptions would need to be clearly defined, however, and we recommend that DFIs disclose and justify any waiver decisions. 


\subsection{Pillar Four: Paris-Aligned Transparency Requires Reporting and Disclosure by Fls and DFIs on Subprojects and on Progress toward Paris Alignment}

Transparency is a prerequisite to ensuring accountability on Paris alignment commitments. A lack of transparency as to what $\mathrm{FI}$ clients are investing in limits DFIs' ability to conduct due diligence, mitigate risks, and meet their public interest mandate (Oxfam 2018). DFls need to require that Fls report on the end use of funds and disclose this information to demonstrate alignment of their Fl investments.

Figure 9 outlines proposed criteria for DFls to assess the alignment of $\mathrm{Fl}$ investments with transparency and reporting requirements.

In phase 1, we recommend that DFIs require Fls to adopt the following transparency and disclosure procedures to ensure that they can demonstrate that DFI funds are not supporting misaligned investments.

1. On an annual basis, Fls would provide detailed reporting to DFIs on their current portfolios. This would include the sectoral breakdown of the portfolios and exposure to any activities on a Paris alignment exclusion list. Reporting would demonstrate consistent reduction in portfolio exposure to misaligned activities. DFIs could support Fls in reporting by providing lists of sectors and activities that typically have significant GHG emissions. FI reporting on its portfolio exposure would be an important prerequisite for DFIs to review the portfolio and understand for which sectors and sector categories the FI would need to develop Paris alignment criteria. For example, the IFC recently started to require that its equity clients publicly disclose their exposure to coal-related projects on an annual basis-information the IFC plans to publish on its project disclosure portal (IFC 2020b).

DFIs can further support clients in identifying exposure to misaligned activities. For example, the IFC asks its FI clients to use a list of companies engaged in coal-related activities developed by the NGO Urgewald to determine their level of coal exposure (Urgewald 2020). DFIs could collaborate among themselves and with NGOs and academia to develop and maintain further lists of companies engaged in other misaligned activities and provide them to Fl clients.

2. Fls would annually provide disaggregate data on the subprojects they invested in using DFI funds. This information would include the borrower's name, project location by city and sector, the results of any environmental and social impact assessments, and the results of the Paris alignment assessment conducted for the project. The Paris alignment assessment would require Fls to assess whether a subproject meets the criteria detailed in Sections 2.3 and 2.4. It would thus include subproject-level results of physical and transition risk assessments and any other Paris alignment investment criteria applied. It could also be consolidated with environmental and social impact assessment documents. Reporting on subprojects with high climate-related risks would take place before project approval. DFIs would verify this reporting on a sample basis.

3. Fls would annually report on their progress in implementing Paris alignment criteria (see Sections 2.3 to 2.5 ) across all its operations over the next five years.

Once verified, DFIs would disclose the abovementioned subproject-level information, Paris alignment criteria, 


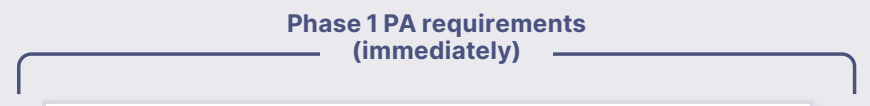

Does the FI report the sectoral breakdown of its portfolio and its exposure to a PA negative list?
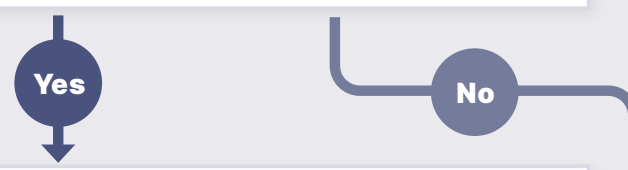

Does the FI report PA and basic info for all subprojects benefiting from MDB/DFI proceeds?
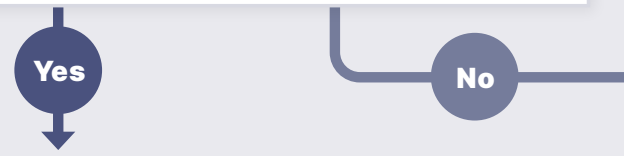

Does the $\mathrm{Fl}$ annually report its progress in implementing further PA criteria in line with the phased approach?
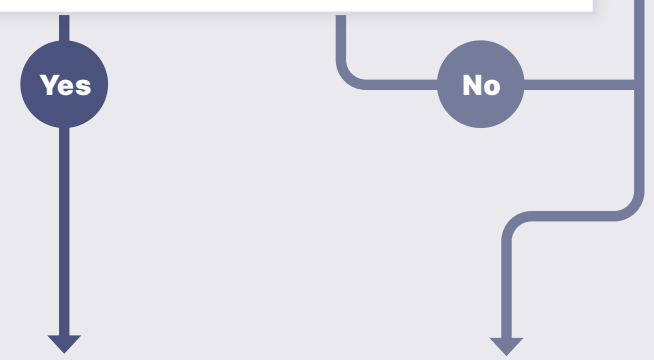

\section{ALIGNED (TRANSPARENCY)}

\section{MISALIGNED}

Phase 2 PA requirements

(within max. 5 years)

Does the FI report the sectoral breakdown of its portfolio and its exposure to a PA negative list?
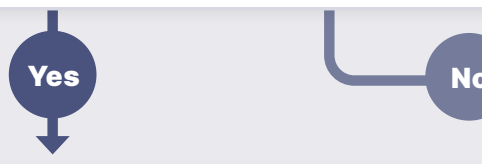

No

Does the FI report PA and basic info for all subprojects benefiting from MDB/DFI proceeds?

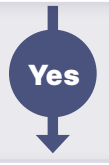

No

Does the $\mathrm{Fl}$ annually report its progress in implementing further PA criteria in line with the phased approach?

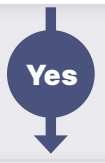

No

Does the FI disclose its share of climate finance?

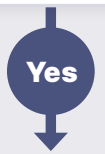

No

Does the FI disclose according to TCFD guidelines?

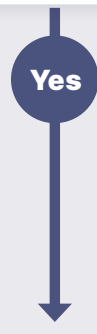

No

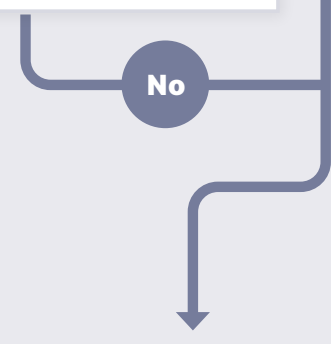

ALIGNED (TRANSPARENCY)
Note: Abbreviations: PA: Paris alignment; FI: financial intermediary; MDB: multilateral development bank; DFI: development finance institution; TCFD: Task Force on

Climate-Related Financial Disclosures.

Source: Authors. 
and climate-related metrics provided by FI clients as part of the project documents listed on their websites. They would also disclose the results of supervising the implementation of requirements on a sample basis.

DFIs often raise confidentiality concerns in disclosing subproject-level information. However, NGO reports show that the duty of confidentiality to clients can often be waived by agreement with the client and, in

\section{Box 1. The TCFD Framework}

The Task Force on Climate-Related Financial Disclosures (TCFD) was established in 2015 by the Financial Stability Board to provide companies, including financial intermediaries, with a structure and approach to understanding climate risks and opportunities and thereby better inform investors, stakeholders, and partners about internal approaches to climate risks.

The task force developed recommendations that are applicable to organizations across sectors and provided supplementary guidance for financial institutions. It found a need for comprehensive, forward-looking management and disclosure of climate risks and opportunities with respect to banks' governance, strategy, and risk management, in addition to metrics and targets that guide operations.

To date, four of the analyzed development finance institutions-the European Bank for Reconstruction and Development, IDB (Inter-American Development Bank) Invest, International Finance Corporation, and KfW (Kreditanstalt für Wiederaufbau; Credit Institute for Reconstruction) Group-have committed to disclose according to the TCFD guidelines.

Source: TCFD n.d. some jurisdictions, if it is in the public interest to do so (Oxfam 2018; BankTrack 2019; Inclusive Development International et al. 2016). DFIs could make the case for greater transparency and support Fls in obtaining consent for disclosure from their clients.

The IFC has taken some steps toward greater transparency, committing to disclosing basic information-including name, location, and sector-on higher-risk FI subprojects financed using IFC funds. It has also committed to making $\mathrm{FI}$ subprojects searchable on the IFC's project disclosure portal (Malpass 2020). Where there is a legal barrier to disclosure, IFC requires clients to provide the specific legal reference and explanation for nondisclosure. Other DFIs have yet to take comparable steps; we recommend that they do so. We also recommend that DFIs go further to disclose relevant project and climate information for all $\mathrm{FI}$ projects, excluding microfinance credit lines.

We further recommend that DFIs aim to harmonize their FI Paris alignment reporting standards. Harmonized reporting metrics would allow for comparability of Paris alignment results across FIs and DFIs, make reporting more practicable for Fls working with multiple DFls, and avoid the risk of DFI arbitrage on the part of Fls.

Under our proposed approach, FI reporting and disclosure requirements would extend in phase 2 to include the following:

1. Reporting on the climate-positive contributions of FI portfolios, such as the share of climate finance used for and disaggregated information on climate finance projects.

2. Reporting in line with the Task Force on ClimateRelated Financial Disclosures (TCFD; see Box 1). This would require Fls to publicly disclose information on their transition risks, physical risks, and climate governance and to provide information on managing future climate risks and making use of climaterelated opportunities. 
As part of the TCFD approach, we recommend that Fls engage their clients on climate risks and opportunities, as well as TCFD-compatible disclosure. Fls could ask their clients to fill out questionnaires on the transition and physical risks of their operations. DFIs that have experience in TCFD-based disclosure and the assessment of climate-related risks could offer to train FI staff and provide useful reporting templates and materials. DFIs would ask Fls to commit to these additional requirements within five years. A DFI could also consider providing incentives for improving disclosure beyond the minimum requirements. For example, IDB Invest offers interest rate discounts for FIs willing to join TCFD and follow its recommendations for analyzing and reporting exposure to financial risks (Meirovich 2020).

\subsubsection{Exceptions and special cases}

Fls that are uniquely engaged in non-emissive activities that are not vulnerable to climate change could also have reduced transparency obligations. They would, however, also need to report basic information on all subprojects benefiting from DFI funds. In addition, they would annually report on lending activities in new sectors to ensure that they do not start supporting misaligned activities.

\subsection{Both Incentives and Penalties May Be Necessary to Ensure Fls' Transition}

To achieve alignment objectives, DFIs can use positive incentives to motivate and enable Fls to comply with alignment criteria. For example, the FI and DFI might agree that the FI needs to refer subprojects to the DFI for in-depth climate risk assessments for a period of up to five years while the FI develops the capacity to conduct those assessments on its own. However, the DFI could encourage the FI to develop the necessary processes and expertise on an expedited basis (e.g., over three years) by offering additional grant resources to do so or some other incentive, such as a lower interest rate at loan maturity.
In the event of non-compliance, sanctions may be a necessary tool for ensuring all indirect DFI investments are Paris aligned by phase 2 . Clients that cannot prove full implementation of all Paris alignment criteria after a maximum of five years would be sanctioned through penalty interest rates and exclusion from further financing.

Sanctions and incentives should be legally binding, contractual requirements between the DFI and FI. Harmonization of Paris alignment approaches, requirements, and sanctions among DFIs and other investors is key to minimizing the bureaucratic burden on Fls-and therefore the risk that Fls will turn to alternative lenders with lower climate reporting standards.

Box 2. Example of an Inter-American Development Bank Incentive-Based Financial Product to Achieve Climate Outcomes

The Inter-American Development Bank created an incentive-based Covid-19 liquidity product in 2020 , where the interest rate is payable only at maturity. The financial intermediary (FI) benefits from lower interest rates or the option to opt for tenor extension if, by the end of the tenor of the loan, it meets predefined climate change-related milestones. These include subproject-level criteria (use-of-proceeds milestones) as well as institutional-level criteria (corporate milestones) for Fls, including reporting annually to the Task Force on Climate-Related Financial Disclosures and growing green portfolios by a predetermined amount.

Source: Meirovich 2020. 


\section{DFIEngagement and Support for Fls Not Ready to Commit to Implementing Paris Alignment Criteria within the Required Timeline}

Some Fls might be willing to make a high-level commitment to align their financial flows with the Paris Agreement but not be ready to commit to the Paris alignment criteria within the proposed timeline. It is potentially valuable for DFIs to continue to engage with these FI partners; DFIs could, for example, highlight the value of integrating climate-related considerations into $\mathrm{Fl}$ operations or support them in developing concrete plans for Paris alignment. We suggest that this continued engagement be done through measures to support capacity building and the use of special purpose vehicles (SPVS), under certain conditions.

In contrast, DFIs should not continue lending relationships with Fls that are generally not willing to align their financial flows with the Paris Agreement and refuse to engage in this way.

\subsection{DFIs Can Help Fls Develop Paris Alignment Capacity}

DFls could support capacity-building efforts to help Fls identify and understand climate risks, develop the governance structures and tools needed to address those risks, and take concrete steps toward alignment.

An Fl's unwillingness to commit to concrete Paris alignment criteria and a timeline for implementation may stem from a lack of awareness and understanding of climate-related risks and opportunities. The better an FI understands climate risks and opportunities, the more likely it is to engage with DFIs on a Paris alignment process. One entry point for engagement between the $\mathrm{DFI}$ and $\mathrm{FI}$ on climate risk may be to include $\mathrm{FI}$ staff in workshops and trainings where the DFI discusses issues related to climate risk and Paris alignment. Further, advisory and consultative services to support the Fl's ability to conduct risk screening and disclose under the TCFD (see Box 1) may enhance understanding about the importance of Paris alignment. Over time, this may lead the Fl to prioritize the development of necessary governance structures and strategies, including a climate strategy, to take steps to minimize climate risk in its portfolio, and to make a formal commitment to Paris alignment.

\subsection{DFls Can Support Fls' Paris Alignment Efforts by Providing Funding via Special Purpose Vehicles}

Another option for a DFI to engage with an $\mathrm{Fl}$ that is committed to Paris alignment but not yet compliant with the proposed alignment criteria would be to work with the FI to establish a mechanism to channel finance exclusively to Paris-aligned lending activities. Such financing would be provided for a set of predetermined activities and structured to minimize the risk that funds will "leak" to misaligned investment activities, either directly or indirectly.

One approach to avoid inadvertently supporting misaligned activities is to establish an SPV that would have clear separation from the Fl's balance sheet and core lending. Paris-aligned SPV finance differs from the common practice of earmarking, or ring-fencing, a credit line for specified environment- or climate-friendly investments-often referred to as green credit lines. As introduced in Section 2, earmarking investments does not eliminate the risk of leakage, as the terms of a green credit line may affect the Fl's overall weighted average cost of capital and indirectly support non-earmarked "dirty" activities. For example, in Models A and B in Figure 10 , the $\mathrm{Fl}$ repays debt (or pays earnings to equity owners) from cash flows related to all the activities of the issuer. In Model $B$, the ring-fenced green finance does not change the volume of investment in green projects, and even ring-fenced finance may indirectly benefit non-aligned investments by impacting the financial intermediary's overall cost of capital. In model $C$, green investment is insulated from the rest of the balance sheet, therefore providing at least some leakage protection. This is particularly important when the finance for the green projects enjoys concessional lending terms. 


\section{FIGURE 10 Climate Impact of Ring-Fencing versus Special Purpose Vehicles}

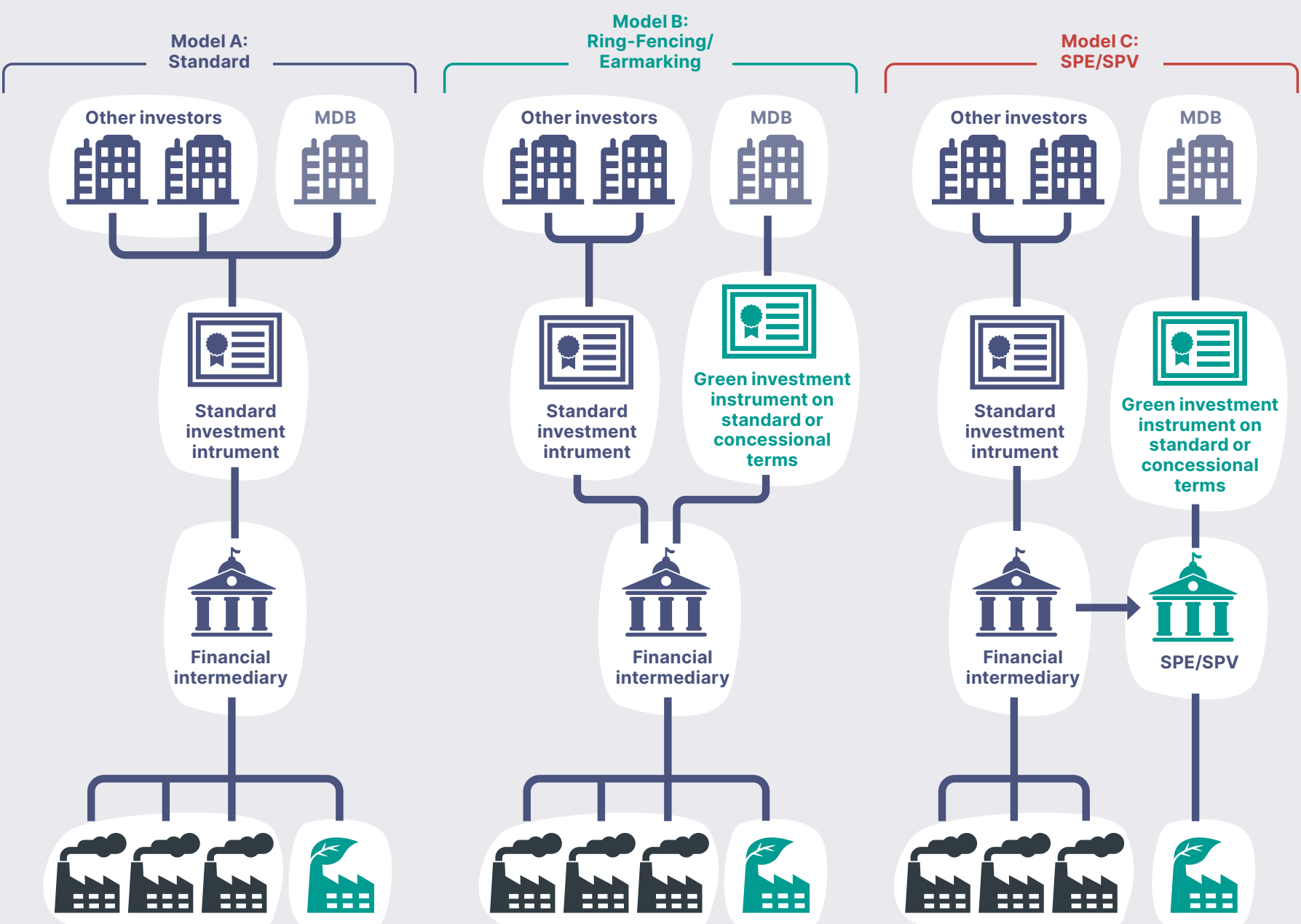

Notes: In Models A and B, the financial intermediary repays debt (or pays earnings to equity owners) from cash flows related to all the activities of the issuer. In Model B, the ring-fenced green finance does not change the volume of investment in green projects, and even ring-fenced finance may indirectly benefit non-aligned investments by impacting the financial intermediary's overall cost of capital. In model $\mathrm{C}$, green investment is insulated from the rest of the balance sheet, therefore providing at least some leakage protection. This is particularly important when the finance for the green projects enjoys concessional lending terms.

Abbreviations: MDB: multinational development bank; SPE: special purpose entity; SPV: special purpose vehicle.

Source: Adapted from Dupre et al. (2018).

This type of engagement could be a valuable way for DFIs to collaborate with FIs on funding for climate action. However, such an option should be available only for a limited time. New FI clients would be eligible for this option only after the DFI had conducted a portfolio risk assessment of the $\mathrm{Fl}$ counterparty (along the lines described in Section 2.1) showing no high risks, such as significant exposure and continued lending to activities on a Paris alignment negative list (especially coal). In addition, DFIs would need to define a positive list of projects that can be financed through an SPV. 


\section{Operational Implications for DFIs}

\section{Ultimately, the onus is on the DFI to ensure that its intermediated finance is Paris aligned. While} many of the mitigation, adaptation, governance, and transparency requirements proposed in Section 2 would fall on Fls to implement, DFIs have a critical role to play in increasing awareness of Paris alignment objectives and financing capacity building. It is the DFIs' responsibility to ensure that Fls adopt the criteria and processes necessary to ensure that their investments through intermediaries are aligned. Consequently, we recommend that DFIs do the following:

1. Ensure that they have the necessary capacity and organizational processes to access, monitor, and disclose the Paris alignment status of Fl investments

2. Develop or update a strategy for Fls that integrates the DFIs' Paris alignment approach and provides guidelines for DFI project managers to assess whether requirements are met

3. Disclose assessments of whether Fls meet mitigation, adaptation, governance, and transparency requirements-including where the Fls stand in terms of capacity and organizational processes, agreed steps, and resources needed to progress toward alignmentand whether and for what period the Fls shall refer projects to the DFI for Paris alignment assessments if the Fls do not meet all immediate requirements

4. Make Paris alignment requirements legally binding by including them in contracts with Fls

5. Monitor whether subprojects meet Paris alignment criteria and disclose disaggregated subproject information

For DFls, engaging more in the approval processes of subprojects will require allocating additional resources. DFI shareholders should thus consider providing additional financing for this purpose. Specific funds or finance facilities could be established to support Fls that are willing to commit to Paris alignment criteria but need capacity support to meet the immediate requirements and establish the necessary processes for assessing projects.

\section{Endnotes}

1. The International Development Finance Club is a coalition of 26 national, regional, and bilateral development banks.

2. However, the multilateral development banks have announced that they will present criteria to align their intermediated lending with the Paris Agreement at the 26th Conference of the Parties scheduled for November 2021.

3. The European Investment Bank (EIB) is furthest along in the process and is starting to implement a number of subproject-level Paris alignment criteria for financial intermediary investments through its "EIB Climate Bank Roadmap 2021-2025," but is also still working on criteria at the institutional level.

4. Namely, the African Development Bank; Asian Development Bank; Asian Infrastructure Investment Bank; European Bank for Reconstruction and Development; European Investment Bank and the private sector-focused European Investment Fund; Inter-American Development Bank and the private sector-focused IDB Invest; Islamic Development Bank and Islamic Corporation for the Development of the Private Sector; New Development Bank; the World Bank and its private sector counterpart, International Finance Corporation; Agence Française de Développement (the French Development Agency) and its private sector lending arm, Proparco; and Kreditanstalt für Wiederaufbau (Credit Institute for Reconstruction) and its private sector lending arm, the Deutsche Investitions- und Entwicklungsgesellschaft (German Investment Corporation).

5. Though the assessment of environment, social, and governance criteria is beyond the scope of this paper, Paris-aligned investments must also ensure, at a minimum, that no significant harm is done to non-climate environmental and social standards as well as human rights.

6. We use 2019 data in Figure 2 and Table 1, as 2020 data were not available for all DFIs as of February 2021.

7. Sustainability certification schemes should be carefully monitored and prohibit both the legal and illegal destruction of high-carbon stock and high-conservation-value ecosystems. For palm oil, Greenpeace International (2013) found that major members of the Roundtable on Sustainable Palm Oil (RSPO) certification scheme continued to be responsible for large-scale deforestation. The German government also found that RSPO needed improvement, a factor that led to an alternative initiative, "Forum Nachhaltiges Palmöl" ("Forum for Sustainable Palm Oil”), in 2013.

8. It is not only the few industries that will become obsolete in a low-carbon economy (e.g., fossil fuel-based power generation) that will be affected by the transition to a net-zero economy-nearly all industries face transition risks and opportunities due to, for example, changing energy prices and other market shifts, as well as policy, legal, and technology changes. Based on a scenario analysis, a solid business model should anticipate potential future changes and include a strategy to respond to them.

9. For more detailed guidance on the data and information to be considered when reporting on climate governance, see TCFD (2017).

10. Threshold derived from AFD's Methodology Guide to the "Sustainable Development Opinion" Mechanism (AFD 2017), where projects above $10,000 \mathrm{tCO}_{2}$ /year are defined as emissive projects. For a definition of scopes, see WBCSD and WRI (2015). 


\section{References}

Acclimatise. n.d. "Acclimatise Aware." Accessed July 1, 2020. http://www. acclimatise.uk.com/analytics/applications/.

ADB (Asian Development Bank). n.d. "ADB Project Database." Accessed May 1, 2020. https://www.adb.org/projects.

ADB. 2009. Safeguard Policy Statement. Appendix 4, Paragraph 15. Manila, Philippines: ADB. https://www.adb.org/sites/default/files/ institutional-document/32056/safeguard-policy-statement-june2009.pdf.

ADB. 2019. Strengthening Accountability Mechanisms in Financial Intermediaries to Support Environmental and Social Sustainability of Subproject. Manila, Philippines: ADB. https://lnadbg4.adb.org/dir0035p. nsf/attachments/FINAL-KnowledgeNote-18Sept2019.pdf/\$FILE/FINALKnowledgeNote-18Sept2019.pdf.

ADB. 2020. "2019 Universal Registration Document."

Manila, Philippines: ADB. https://www.afd.fr/en/

ressources/2019-universal-registration-document.

ADBG (African Development Bank Group). 2017. "One Planet SummitJoint IDFC-MDB Statement-Together Major Development Finance Institutions Align Financial Flows with the Paris Agreement." https:// www.afdb.org/en/news-and-events/one-planet-summit-joint-idfc-mdbstatement-together-major-development-finance-institutions-alignfinancial-flows-with-the-paris-agreement-17685.

ADBG. 2020. Annual Report 2019. Abidjan, Côte d'Ivoire: ADBG. https:// www.afdb.org/en/documents/annual-report-2019.

AFD (Agence Française de Développement; French Development Agency). 2017. Methodology Guide to the "Sustainable Development Opinion" Mechanism. Paris: AFD. https://www.afd.fr/en/ressources/ methodology-guide-sustainable-development-opinion-mechanism.

AFD. 2020a. "Booklet Finance in Common Summit." Paris: AFD.

AFD. 2020b. "Six Things to Know about Public Development Banks." Paris: AFD. https://www.afd.fr/en/actualites/ six-things-know-about-public-development-banks.

Ahman, M. n.d. "Perspective: Unlocking the 'Hard to Abate' Sectors." Expert Perspectives. Washington, DC: World Resources Institute. https:// www.wri.org/climate/expert-perspective/unlocking-hard-abate-sectors.

AllB (Asian Infrastructure Investment Bank). n.d. "AllB Project Database." Accessed May 1, 2020. https://www.aiib.org/en/projects/list/.

AllB. 2020. Review Draft-Environmental and Social Framework. Beijing: AllB. https://www.aiib.org/en/policies-strategies/_download/ environment-framework/AllB-Review-Draft-Environmental-and-SocialFramework_Sept-7-2020.pdf.

Arneth, A., H. Barbosa, T. Benton, K. Calvin, and E. Calvo. 2019. Summary for Policymakers in Climate Change and Land: An IPCC Special Report on Climate Change, Desertification, Land Degradation, Sustainable Land Management, Food Security, and Greenhouse Gas Fluxes in Terrestrial Ecosystems. Geneva: Intergovernmental Panel on Climate Change. https://www.ipcc.ch/srccl/chapter/ summary-for-policymakers/.
BankTrack. 2019. We Are Unable to Comment on Specific Customers...: Challenging Banks on Client Confidentiality. BankTrack Briefing. Nijmegen, Netherlands: BankTrack. https://www.banktrack.org/ download/we_are_unable_to_comment_on_specific_clients/191105weare unabletocomment.pdf.

BIC Europe and SOMO (Bank Information Center Europe [now Recourse] and Centre for Research on Multinational Corporations). 2018. Coming Out of the Dark. Is the IFC Investing in a Fossil Free Future? Amsterdam: BIC Europe and SOMO. https://www.re-course.org/wp-content/ uploads/2018/11/Coming-Out-of-the-Dark-November-2018-1.pdf.

CAO (Compliance Advisor Ombudsman). 2012. CAO Audit of a Sample of IFC Investments in Third-Party Financial Intermediaries. Washington, DC: CAO. http://www.cao-ombudsman.org/newsroom/documents/ Audit_Report_C-I-R9-Y10-135.pdf.

Climate Action Tracker. 2020. "Paris Agreement Compatible Sectoral Benchmarks." https://climateactiontracker.org/documents/754/ CAT_2020-07-10_ParisAgreementBenchmarks_SummaryReport.pdf.

Curmally, A., J. Sohn, and C. Wright. 2005. Multilateral Development Bank Lending through Financial Intermediaries: The Environmental and Social Challenges. Washington, DC: World Resources Institute. https://www.wri.org/publication/ multilateral-development-bank-lending-through-financial-intermediaries.

DEG (Deutsche Investitions- und Entwicklungsgesellschaft; German Investment Corporation). n.d. "Project Database." Accessed May 1, 2020. https://deginvest-investments.de/.

DEG. 2020. Annual Report 2019. Financial Statements and Management Report. Cologne, Germany: DEG. https://www. deginvest.de/DEG-Documents-in-English/Download-Center/ DEG_Annual_Report_2019_EN.pdf.

Dupre, S., T. Wang, and T. Jamison. 2018. Shooting for the Moon in a Hot Air Balloon? Measuring How Green Bonds Contribute to Scaling Up Investments in Green Projects. Paris: $2^{\circ}$ Investing Initiative. https://2degrees-investing.org/wp-content/uploads/2020/01/2018Green-bonds-updated-paper.pdf.

EBRD (European Bank for Reconstruction and Development). n.d. "Project Summary Documents." Accessed May 1, 2020. https://www. ebrd.com/work-with-us/project-finance/project-summary-documents. html?keywordSearch $=$.

EBRD. 2018. Credit Lines_Lending through Financial Intermediaries. Evaluation Department. London: EBRD.

EBRD. 2020. Annual Review 2019. London: EBRD. https://www.ebrd.com/ news/publications/annual-report/ebrd-annual-review-2019.html.

EIB (European Investment Bank). n.d. "EIB Project Database." Accessed May 1, 2020. https://www.eib.org/en/projects/loans/index. htm?q=\&sortColumn=loanParts. loanPartStatus. statusDate\&sortDir=des c\&pageNumber $=0$ \&itemPerPage $=25$ \& pageable $=$ true\&language $=\mathrm{EN} \&$ def aultLanguage $=$ EN\&loanPartYearFrom $=1959 \&$ loanPartYearTo $=2021 \&$ orC ountries.region=true \&orCountries=true\&orSectors $=$ true. 
EIB. 2017. Operations Evaluation: Evaluation of EIB Intermediated Lending through the Investment Facility in ACP. Kirchberg, Luxembourg: EIB. https://www.eib.org/attachments/ev/ ev_intermediated_lending_if_acp_en.pdf.

EIB. 2020a. Data on Guarantees and Equity/Quasi-equity in 2019 Provided by EIB Civil Society Unit on Request. Kirchberg, Luxembourg: EIB.

EIB. 2020b. "EIB Website: Investments in Infrastructure and Environmental Funds." https://www.eib.org/en/products/equity/infraenvironment-funds/index.htm.

EIB. 2020c. Statistical Report 2019. Kirchberg, Luxembourg: EIB. https://www.eib.org/attachments/general/reports/ eib_statistical_report_2019_en.pdf.

ETC (Energy Transitions Commission). 2018. Mission Possible. Reaching Net-Zero Carbon Emissions from Harder-to-Abate Sectors by Midcentury. London: ETC. https://www.energy-transitions.org/publications/ mission-possible/.

EU TEGSF (European Union Technical Expert Group on Sustainable Finance). 2019. Taxonomy Technical Report. Brussels: European Commission. https://ec.europa.eu/info/ sites/info/files/business_economy_euro/banking_and_finance/ documents/190618-sustainable-finance-teg-report-taxonomy_en.pdf.

Germanwatch and NewClimate Institute. 2018. Aligning Investments with the Paris Temperature Goal: Challenges and Opportunities for Multilateral Development Banks. Bonn, Germany: Germanwatch; Berlin: NewClimate Institute.

Greenpeace International. 2013. Certifying Destruction: Why Consumer Companies Need to Go beyond the RPSO to Stop Forest Destruction. Amsterdam: The Netherlands: Greenpeace International. https://www. greenpeace.org/static/planet4-sweden-stateless/2019/01/69d1a6b869d1a6b8-rspo-certifying-destruction.pdf.

14CE (Institute for Climate Economics). 2019. A Framework for Alignment with the Paris Agreement: Why, What and How for Financial Institutions? Paris: I4CE. https://www.i4ce.org/download/framework-alignment-withparis-agreement-why-what-and-how-for-financial-institutions/.

ICD (Islamic Corporation for the Development of the Private Sector). 2020. Annual Report 2019. 20 Years Is Our Heritage. But the Future Is Our Legacy. Jeddah, Saudi Arabia: ICD. https://icd-ps.org/uploads/files/ ICD\%20Annual\%20Report\%202019\%20EN1591870437_6879.pdf.

IDB (Inter-American Development Bank). n.d. "Project Database." Accessed May 1, 2020. https://www.iadb.org/en/projects-search.

IDB. 2020. "Environmental and Social Policy Framework." https://www. iadb.org/en/mpas.

IDB Invest. n.d. "Project Database." Accessed May 1, 2020. https://www. idbinvest.org/en/projects.

IFC (International Finance Corporation). n.d. "IFC Project Database." Accessed May 1, 2020. https://finances.worldbank.org/Projects/ IFC-Investment-Services-Projects/efin-cagm.
IFC. 2018. "Interpretation Note on Financial Intermediaries." https://www.ifc.org/wps/wcm/connect/topics_ext_content/ ifc_external_corporate_site/sustainability-at-ifc/publications/ publications_policy_interpretationnote-fi.

IFC. 2020a. Annual Report 2019. Investing for Impact. Washington, DC: IFC. https://www.ifc.org/wps/wcm/connect/4ffd985dc160-4b5b-8fbe-3ad2d642bbad/IFC-AR19-Full-Report. pdf?MOD=AJPERES\&CVID $=m V 2 u Y F U$.

IFC. 2020b. "IFC's Approach to Greening Equity Investments in Financial Institutions." Washington, DC: IFC. https://www.ifc.org/ wps/wcm/connect/05541643-0001-467d-883c-5d7a127ffd57/ IFC+Greening+Report+Sept+2020.pdf?MOD=AJPERES\&CVID=nisvaOC\& ContentCache $=$ NONE\&CACHE $=$ NONE.

Inclusive Development International, Bank Information Center Europe, and Philippine Movement for Climate Justice. 2018. Broken Promises.

The World Bank, International Investors and the Fight for Climate Justice in the Philippines. Asheville, North Carolina: Inclusive Development International; Amsterdam: Bank Information Center Europe; Quezon City, Philippines: Philippine Movement for Climate Justice. https://www. inclusivedevelopment.net/wp-content/uploads/2020/01/philippinescoal-report.pdf.

Inclusive Development International, Grow, and Oxfam. 2016. Owning the Outcomes. Time to Make the World Bank Group's Financial Intermediary Investments More Accountable. OXFAM Briefing Note. Oxford: United Kingdom: Oxfam. https://www.inclusivedevelopment.net/wp-content/ uploads/2016/09/bn-ifc-owning-outcomes-031016-en.pdf.

IsDB (Islamic Development Bank). 2020. Annual Report 2019. Shaping New Frontiers for Sustainable Development. Jeddah, Saudi Arabia: IsDB. https://www.isdb.org/sites/default/files/media/ documents/2020-06/1\%20Annual\%20Report\%202019\%20English\%20 Cleared.pdf.

KfW (Kreditanstalt für Wiederaufbau, Germany; Credit Institute for Reconstruction). n.d. "Transparency Portal on Development Finance." Accessed May 1, 2020. https://www.kfw.de/microsites/Microsite/ transparenz.kfw.de/\#/start.

Kuramochi, T., N. Hohne, M. Hagemann, and S. Sterl. 2016. "The Ten Most Important Short-Term Steps to Limit Warming to $1.5^{\circ} \mathrm{C}$." Climate Action Tracker. https://climateactiontracker.org/documents/108/ CAT_2016-11-16_10StepsFullReport_PolicyBrief.pdf.

Kuramochi, T., N. Höhne, M. Schaeffer, J. Cantzler, B. Hare, Y. Deng, S. Sterl, et al. 2018. "Ten Key Short-Term Sectoral Benchmarks to Limit Warming to $1.5^{\circ} \mathrm{C}$." Climate Policy 18 (3): 287-305. https://doi.org/10.108 0/14693062.2017.1397495.

Larsen, G., C. Smith, N. Krishnan, L. Weischer, S. Bartosch, and H. Fekete. 2018. Toward Paris Alignment: How the Multilateral Development Banks Can Better Support the Paris Agreement. Washington, DC: World Resources Institute; Berlin: NewClimate Institute; Bonn, Germany: Germanwatch; Washington, DC: Fundación Avina. https://germanwatch. org/en/16085. 
Lebling, K., M. Ge, K. Levin, and R. Waite. 2020. State of Climate Action: Assessing Progress toward 2030 and 2050. Washington, DC: World Resources Institute. https://www.wri.org/research/ state-climate-action-assessing-progress-toward-2030-and-2050.

Malpass, D. 2020. "Letter to the Secretary of the US Treasury. March 20, 2020." Washington, DC: World Bank Group. https://financialservices. house.gov/uploadedfiles/malpass_Itr_mnuchin_3202020.pdf.

Meirovich, H. 2020. "Let's Use Financial Engineering for Good, with a New Structured Product." Blog. IDB Invest. https://idbinvest.org/en/blog/financial-institutions/ lets-use-financial-engineering-good-new-structured-product.

NDB (New Development Bank). n.d. "Project Database." Accessed May 1, 2020. https://www.ndb.int/projects/list-of-all-projects/ approved-projects/.

Oxfam. 2018. Open Books. How Development Finance Institutions Can Be Transparent in Their Financial Intermediary Lending and Why They Should Be. Oxford, United Kingdom: Oxfam. https://oxfamilibrary. openrepository.com/bitstream/handle/10546/620559/bp-financialinstitutions-disclosure-161018-en.pdf.

Oxfam. 2020. "Learning from 10 Years of Campaigning on Financial Intermediary Lending at the International Finance Corporation." https:// oxfam.app.box.com/s/rs5c5ndh89ihnhj343fkwzow127hq686.

Proparco. n.d. "Project Database." Accessed May 1, 2020. https://opendata.afd.fr/explore/dataset/donnees-de-laide-audeveloppement-de-proparco/table/?dataChart=eyJxdWVyaWVzljpbey Jjb25maWciOnsiZGFOYXNIdCI6ImRvbm5IZXMtZGUtbGFpZGUtYXUtZG V2ZWxvcHBIbWVudC1kZS1wcm9wYXJjbylsIm9wdGIvbnMiOnt9fSwiY 2hhcnRzljpbeyJhbG\&sort=-date_de_signature.
TCFD (Task Force on Climate-Related Financial Disclosures). n.d. "TCFD Supporters." Accessed April 30, 2021. https://www.fsb-tcfd.org/ supporters/.

TCFD. 2017. Final Report: Recommendations of the Task Force on Climate-Related Financial Disclosure. New York: TCFD. https:// www.fsb-tcfd.org/wp-content/uploads/2017/06/FINAL-2017-TCFDReport-11052018.pdf.

UNFCCC (United Nations Framework Convention on Climate Change). 2015. Paris Agreement. Paris: UNFCCC. https://unfccc.int/sites/default/ files/english_paris_agreement.pdf.

Urgewald. 2020. "Global Coal Exit List 2020.” https://coalexit.org/.

WBCSD and WRI (World Business Council for Sustainable Development and World Resources Institute), eds. 2015. The Greenhouse Gas Protocol: A Corporate Accounting and Reporting Standard. Revised Edition. Geneva: WBCSD; Washington, DC: World Resources Institute. https://ghgprotocol.org/corporate-standard.

Westphal, M., and L. Sidner. 2020. Enhancing Adaptation and ClimateResilient Operations within the Multilateral Development Banks. Bonn, Germany: Germanwatch; Berlin: NewClimate Institute; and Washington, DC: World Resources Institute. https://www.germanwatch.org/en/17309.

World Bank. n.d. "Project Database." Accessed May 1, 2020. https:// projects.worldbank.org/en/projects-operations/projects-list. 


\section{Acknowledgments}

Leonardo Martinez-Diaz was instrumental in helping to structure, draft, and edit this report. We are also grateful for valuable research provided by Sarah Ribbert and Daniel Gulde. The authors would also like to thank the following individuals for their insightful comments and critical reviews: Zach Malik, Kate Geary, Christian Donaldson, Xavier Sol, Ladd Connell, Knud Vöcking, Heike Mainhardt, Leo Theobaldt, Christoph Bals, Frauke Röser, Gaia Larsen, Jacob Waslander, Amy Meyer, Julie Bos, and Tirthankar Mandal. Finally, the authors are grateful to staff and management at ADB, AfDB, AIIB, EBRD, EIB, EIF, IDB, IDB-Invest, IsDB, NDB, World Bank, IFC, AFD, and KfW who contributed generous amounts of time to share information about their work, participate in meetings to discuss this research, review this working paper, and contribute to panel discussions with the consortium.

This working paper received financial support from the Federal Ministry for Economic Cooperation and Development of Germany (BMZ). The authors are solely responsible for the content of this publication.

Supported by:

Bundesministerium für
wirtschaftliche Zusammenarbeit
und Entwicklung

\section{About the Authors}

\author{
Sophie Fuchs \\ Policy Advisor - Development Banks and Climate, Germanwatch \\ CONTACT: fuchs@germanwatch.org
}

Aki Kachi

Climate Finance and Carbon Markets, NewClimate Institute GmbH

CONTACT: a.kachi@newclimate.org

\section{Lauren Sidner}

Research Associate, WRI Sustainable Finance Center

CONTACT: Lauren.Sidner@wri.org

Michael Westphal

Congressional Research Service

CONTACT: miwestphal@gmail.com

\section{About Germanwatch}

Following the motto of Observing. Analysing. Acting. Germanwatch has been actively promoting global equity and livelihood preservation since 1991. We focus on the politics and economics of the Global North and their world-wide consequences. The situation of marginalized people in the Global South is the starting point for our work. Together with our members and supporters, and with other actors in civil society, we strive to serve as a strong lobbying force for sustainable development. We aim at our goals by advocating for prevention of dangerous climate change and its negative impacts, for guaranteeing food security, and for corporate compliance with human rights standards.

\section{About NewClimate}

NewClimate Institute supports research and implementation of action against climate change around the globe. We generate and share knowledge and ideas on international climate negotiations, tracking climate action, climate and development, climate finance, and carbon market mechanisms. We connect up-to-date research with the real world decision-making processes, making it possible to increase ambition in acting against climate change and contributing to finding sustainable and equitable solutions.

\section{About WRI}

World Resources Institute is a global research organization that turns big ideas into action at the nexus of environment, economic opportunity, and human well-being.

\section{Our Challenge}

Natural resources are at the foundation of economic opportunity and human well-being. But today, we are depleting Earth's resources at rates that are not sustainable, endangering economies and people's lives. People depend on clean water, fertile land, healthy forests, and a stable climate. Livable cities and clean energy are essential for a sustainable planet. We must address these urgent, global challenges this decade.

\section{Our Vision}

We envision an equitable and prosperous planet driven by the wise management of natural resources. We aspire to create a world where the actions of government, business, and communities combine to eliminate poverty and sustain the natural environment for all people. 